\title{
Single Molecule Magnets
}

DOI:

10.1002/9781119951438

\section{Document Version}

Accepted author manuscript

Link to publication record in Manchester Research Explorer

\section{Citation for published version (APA):}

Giansiracusa, M., Gransbury, G., Chilton, N., \& Mills, D. (2021). Single Molecule Magnets. In Encyclopedia of Inorganic and Bioinorganic Chemistry [eibc2784] John Wiley \& Sons Ltd. https://doi.org/10.1002/9781119951438

\section{Published in:}

Encyclopedia of Inorganic and Bioinorganic Chemistry

\section{Citing this paper}

Please note that where the full-text provided on Manchester Research Explorer is the Author Accepted Manuscript or Proof version this may differ from the final Published version. If citing, it is advised that you check and use the publisher's definitive version.

\section{General rights}

Copyright and moral rights for the publications made accessible in the Research Explorer are retained by the authors and/or other copyright owners and it is a condition of accessing publications that users recognise and abide by the legal requirements associated with these rights.

\section{Takedown policy}

If you believe that this document breaches copyright please refer to the University of Manchester's Takedown Procedures [http://man.ac.uk/04Y6Bo] or contact uml.scholarlycommunications@manchester.ac.uk providing relevant details, so we can investigate your claim.

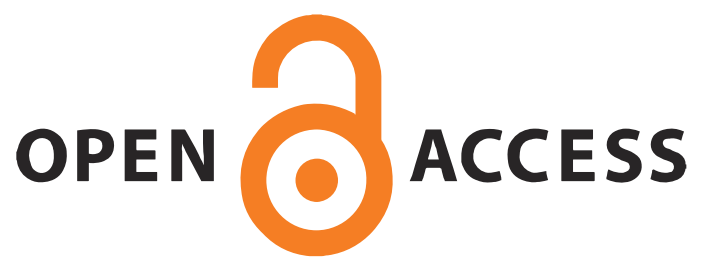




\title{
Single Molecule Magnets
}

Article Unique ID: eibc2784

Marcus J. Giansiracusa, ${ }^{I}$ Gemma K. Gransbury, ${ }^{1}$ Nicholas F. Chilton, ${ }^{l}$ and David P. Mills $* 1$

${ }^{1}$ Department of Chemistry, The University of Manchester, Oxford Road, Manchester, M13 9PL, UK.

*Tel: +44(0)1612754606

*Email: david.mills@manchester.ac.uk

Filename: EIBC_2020_resubmit_FINAL.docx (Microsoft Word 2016)

Figure filenames: Figurex.tif $(\mathrm{x}=1-17)$

$\begin{array}{ll}1 \text { INTRODUCTION } & 2 \\ 2 \text { MEASUREMENTS AND MECHANISMS } & 3 \\ 3 \text { POLYMETALLIC 3d SINGLE-MOLECULE MAGNETS } & 7 \\ 4 \text { MONOMETALLIC 4f SINGLE-MOLECULE MAGNETS } & 8 \\ 5 \text { MONOMETALLIC 3d SINGLE-MOLECULE MAGNETS } & 11 \\ \text { 6 EXCHANGE-COUPLED SINGLE-MOLECULE MAGNETS } & 13 \\ 7 \text { PERSPECTIVES } & 15 \\ \text { 8 SUMMARY } & 15 \\ \text { 9 ACKNOWLEDGEMENTS } & 15 \\ \text { 10 RELATED ARTICLES } & 15 \\ \text { 11 REFERENCES } & 15\end{array}$

\begin{abstract}
Single-Molecule Magnets (SMMs) are finite molecular species that display slow relaxation of their magnetisation, equivalent to a magnetic memory effect. Here we give an overview of how SMM behaviour can arise from the spin properties of a giant molecular spin or unpaired electrons on a single metal centre. We outline the criteria for obtaining SMM properties, and how these have developed through theoretical insight to lead to the rapid advancement of SMM performance. We discuss the progression of the field from the original $\mathrm{Mn}_{12}$ polymetallic cluster, to carefully engineered coordination complexes of $\mathrm{Ln}$ ions. Classes of compounds discussed include $3 \mathrm{~d}, 3 \mathrm{~d}-4 \mathrm{f}$ and $4 \mathrm{f}$ polymetallic clusters, $3 \mathrm{~d}$ and $4 \mathrm{f}$ monometallic complexes, and homo- and hetero-metallic exchange-coupled SMMs, including those bridged by radical ligands and/or encapsulated in endohedral fullerenes. The state-ofthe-art in SMMs is discussed, leaving the reader with an up-to-date understanding of theory and synthetic design, with references to comprehensive reviews.

For readers new or returning to the area, we highlight the standard experiments used to characterise SMMs - including magnetic hysteresis, zero-field cooled/field cooled magnetic susceptibility, alternating current susceptibility and magnetisation decay measurements. We highlight the common pitfalls often encountered in the literature in measurements, data analysis and structural correlation of properties. We aim to provide a clear background for relaxation mechanisms in SMMs and the quantification of performance using energy barriers, blocking temperatures and relaxation rate. The reader is directed towards a series of proof-ofconcept publications which have spearheaded the implementation of SMMs towards future applications in high density data storage, quantum information processing and spintronics.
\end{abstract}

Keywords: single-molecule magnet, single-ion magnet, molecular magnetism, slow magnetic relaxation, magnetic anisotropy, hysteresis, quantum tunnelling, transition metal, lanthanide, radical 


\section{INTRODUCTION}

A single-molecule magnet (SMM) is a finite molecular unit capable of displaying slow relaxation of magnetisation without the need for long range ordering. ${ }^{1}$ The observation of SMM behaviour was first identified in 1993 in a $\mathrm{Mn}_{12}$ acetate cluster with the formula $\left[\mathrm{Mnn}^{\mathrm{IV}}{ }_{4} \mathrm{Mn}^{\prime \prime \prime}{ }_{8} \mathrm{O}_{12}\left(\mathrm{O}_{2} \mathrm{CCH}_{3}\right)_{16}\left(\mathrm{H}_{2} \mathrm{O}\right)_{4}\right]$ (Figure 1). ${ }^{2}$ The ability for a single molecule to show retention of magnetisation is an exciting prospect for many applications, including high density data storage and spintronics. ${ }^{3}$

\subsection{Giant Spin SMMs}

For $\mathrm{Mn}_{12}$, the intramolecular exchange interactions between $\mathrm{Mn}^{\mathrm{III} / \mathrm{IV}}$ ions result in an overall total spin ground state of $S=10$, Figure $2{ }^{2}$ The ground state is split into $M_{s}$ components because of magnetic anisotropy (orientationally-dependent energy for the magnetic moment relative to the molecule). This zero field splitting (ZFS) of the ground state can be approximately described by axial $(D)$ and rhombic ( $E$, also called transverse) parameters, as given by the Hamiltonian in Equation 1, where $\hat{S}_{x y z}$ are the Cartesian spin projection operators. ${ }^{1}$

Equation 1: $\widehat{H}_{Z F S}=D\left[\hat{S}_{z}^{2}-\frac{S(S+1)}{3}\right]+E\left(\hat{S}_{x}^{2}-\hat{S}_{y}^{2}\right)$

Molecules with $|D| \gg|E|$ can either favour the magnetic moment along a single axis (negative $D$, conventionally easy zaxis) or in the perpendicular plane (positive $D$, conventionally easy $x y$-plane). Molecules with rhombic anisotropy $(0<|E| \leq$ $|D| / 3)$ have different energies for the magnetic moment along each of the $x, y$ and $z$ directions. ${ }^{1}$
The archetypical SMM is an easy-axis molecule with minimal rhombicity (i.e. $|D|>>|E|$ ). For $\mathrm{Mn}_{12}, D<0$ results in the $M_{s}$ states ordering from most magnetic along the $z$-axis at lowest energy $\left(M_{S}= \pm 10\right)$ up to the least magnetic $\left(M_{S}=0\right.$, i.e. magnetic moment in the $x y$-plane) at highest energy, Figure $2 .^{2}$ This satisfies the first requirement of SMMs by having a bi-stable degenerate ground state. ${ }^{1}$

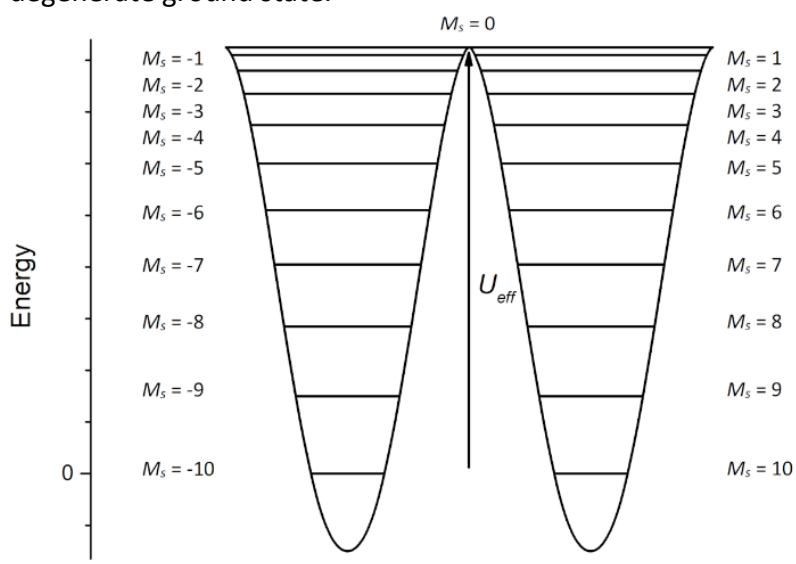

Figure 2. Idealised double-well potential for a $\mathrm{Mn}_{12} \mathrm{SMM}$, where all $M_{s}$ states are ordered in energy from highest $\left|M_{s}\right|$ value to lowest.

The application of a strong magnetic field causes one of the $M_{S}$ $= \pm 10$ states to be biased lower in energy than the other by having a parallel alignment of the magnetic moment with the magnetic field, and at a low enough temperature, an ensemble of molecules in equilibrium shows a significantly larger population in the lower energy state than in the higher. ${ }^{2}$ When
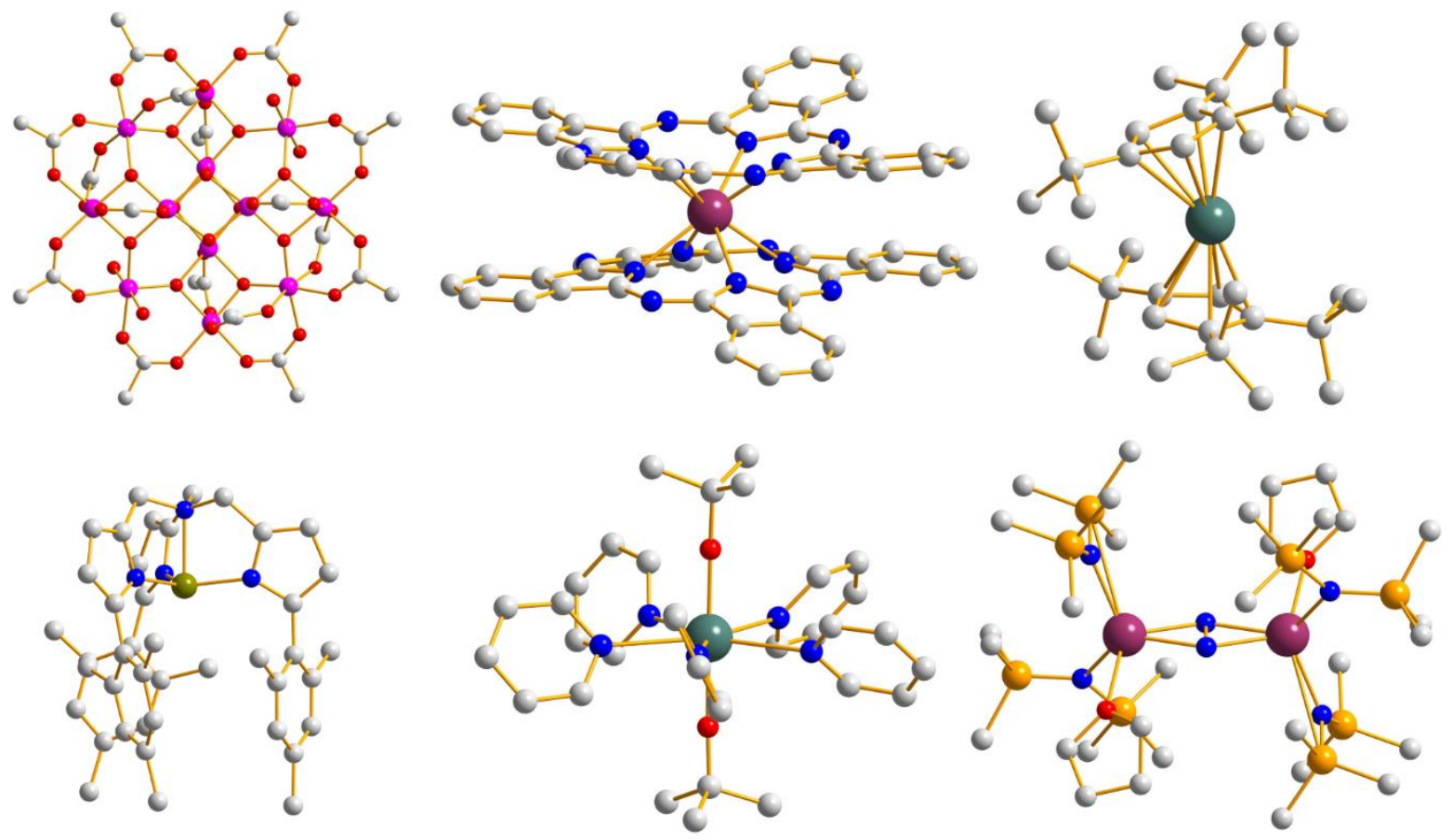

Figure 1. Selected single-molecule magnets mentioned in this article (hydrogen atoms and counterions omitted for clarity). Top row, from left to right: $\left[\mathrm{Mn}^{\mathrm{IV}}{ }_{4} \mathrm{Mn}^{\mathrm{II}}{ }_{8} \mathrm{O}_{12}\left(\mathrm{O}_{2} \mathrm{CCH}_{3}\right)_{16}\left(\mathrm{H}_{2} \mathrm{O}\right)_{4}\right],\left[\mathrm{Tb}(\mathrm{Pc})_{2}\right]^{-}(\mathrm{Pc}=$ phthalocyaninato $),\left[\mathrm{Dy}\left(\mathrm{Cp}^{\mathrm{ttt}}\right)_{2}\right]^{+}\left(\mathrm{Cp}^{\mathrm{ttt}}=\mathrm{C}_{5} \mathrm{H}_{2}{ }^{\mathrm{t}} \mathrm{Bu}{ }_{3}-1,2,4\right)$. Bottom row, from left to right: $\left[\mathrm{Fe}\left(\mathrm{tpa}^{\mathrm{Mes}}\right)\right]^{-}\left(\mathrm{tpa}^{\mathrm{Mes}}=\right.$ mesityl-substituted tris(pyrrolylmethyl)amine $),\left[\mathrm{Dy}\left(\mathrm{O}^{\mathrm{t}} \mathrm{Bu}\right)_{2}(\mathrm{py})_{5}\right]^{+}(\mathrm{py}=$ 
pyridine) and $\left[\left\{\mathrm{Tb}\left[\mathrm{N}\left(\mathrm{SiMe}_{3}\right)_{2}\right]_{2}(\mathrm{THF})\right\}_{2}\left(\mu-\eta^{2}: \eta^{2}-\mathrm{N}_{2}\right)\right]^{-}$. Colour code: dysprosium (teal), terbium (purple), iron (ochre), manganese (pink), oxygen (red), nitrogen (blue), silicon (amber), carbon (grey).

the magnetic field is removed, the $\pm M_{S}$ states recover their degeneracy, but the population bias initially remains: this is magnetic memory. The memory is lost when the population returns to an equal distribution between positive and negative $M_{S}$ microstates. The reversal of magnetisation of individual molecules moving from $+M_{S}$ to $-M_{S}$ states happens slowly because of an energy barrier, and thus, the relaxation of an outof-equilibrium ensemble population back to equilibrium is also slow; an energy barrier to magnetisation reversal is the second requirement for SMMs. ${ }^{1}$

The process of magnetic relaxation in SMMs arises from coupling between vibrations (phonons) and each molecule, socalled spin-phonon coupling, which facilitates transitions between $M_{S}$ states by modulating the ZFS Hamiltonian. The selection rule for spin-phonon transitions turns out to be welldescribed by $\Delta M_{S}= \pm 1 .{ }^{4}$ For a molecule of $M_{12}$ to move from $M_{S}=+10$ to $M_{S}=-10$, it must first traverse each intervening state, $M_{s}=+9, \ldots,+1,0,-1, \ldots,-10 .{ }^{1}$ As a result of the ordering of the states shown in Figure 2, there is a thermal barrier $\left(U_{\text {eff }}\right)$ associated with the reversal of the magnetisation, equal to the height of the double-well potential. In spin-only molecules such as $M_{12}$, the value of $U_{\text {eff }}$ can be related to the axial ZFS parameter, with $U_{\text {eff }}=|D| S^{2}$ for integer spins and $U_{\text {eff }}=|D|\left(S^{2}\right.$ $-1 / 4)$ for half-integer spins; but note that due to other relaxation processes this maximal $U_{\text {eff }}$ barrier is not usually observed. ${ }^{1}$ Early research on SMMs focused on 3d metal clusters, and targeted molecules with large total spin ground states. Giant ground spin states (current record is $S=91$ ) are accessed by coupling the spins of many individual metal ions. ${ }^{5}$ However, magnetic anisotropy is dominated by contributions from orbital angular momentum of unpaired electrons on individual metal ions, so the magnetic anisotropy of a giant spin requires cooperative alignment of the individual anisotropies of the constituent ions, which becomes more difficult with increasing molecule size. ${ }^{6}$ Many $3 d$ clusters which exhibit giant spin ground states show no SMM behaviour. $5,7-10$

\subsection{SMM Properties Arising from Single lons}

In 2003, the complex [ $\left.\mathrm{N}\left({ }^{\mathrm{n} B u}\right)_{4}\right]\left[\mathrm{Tb}(\mathrm{Pc})_{2}\right](\mathrm{Pc}=$ phthalocyaninato; Figure 1) containing a single $4 \mathrm{f}$ ion was found to exhibit SMM properties and was denoted as a single-ion magnet. ${ }^{11,12}$ In this complex, the electronic states responsible for the energy barrier to reversal of magnetisation are the spin-orbit coupled states of $\mathrm{Tb}^{\text {III }}$ and the anisotropy arises from the interplay of these states with the crystal field (CF). The single-ion magnet label is commonly used in the literature to identify SMMs where the properties rely on the single-ion anisotropy, and has since become synonymous with monometallic SMMs. However, as polymetallic SMMs can also have properties that arise from non-interacting paramagnetic centres, in this article we use the terminology monometallic and polymetallic SMMs for clarity.
For lanthanide (Ln) ions, the reduced spatial distribution inherent to $4 f$ orbitals ensures a weak interaction with the CF and hence near-unquenched orbital degeneracy and first-order orbital angular momentum..$^{13}$ The spin-orbit coupled states can be labelled by a Russell-Saunders term, ${ }^{2 S+1} L$, where $S$ is the spin quantum number, $L$ is the orbital angular momentum quantum number and $J$ is the total angular momentum quantum number; $J$ takes values from $|L+S|$ to $|L-S|$. The ground term for a $L n^{\prime \prime I}$ ion $\left({ }^{2 S+1} L J\right)$ is dependent on the number of electrons in the $4 \mathrm{f}$ shell, where less than half filled ( $<7$ electrons) stabilises $J$ $=|L-S|$, while more than half filled $(>7$ electrons) yields a $J=L+S$ ground state. ${ }^{13}$ Each $J$ multiplet comprises $2 J+1 M_{J}$ microstates which are split and mixed by the CF into linear combinations (see eibc2009). Appropriate design of the molecule and CF can

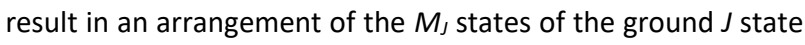
where the most magnetic microstates are lowest in energy. Hence the arrangement of $M_{\text {J }}$ states can also lead to a doublewell potential analogous to the $M_{s}$ states in $\mathrm{Mn}_{12}$. Spin-phonon

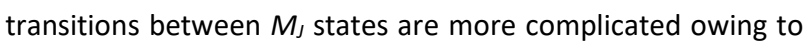
high-order terms in the CF Hamiltonian, but often a $\Delta M_{J}=0, \pm 1$ selection rule is appropriate. ${ }^{14}$ The advantage in designing $L n$ SMMs is that the ground Russell-Saunders term is known and is often well-isolated for each ion, so the problem is simplified to manipulating only the $M_{J}$ states of the ground $J$ manifold of a single ion. ${ }^{13}$ It is important to note that ions with an odd number of unpaired electrons are termed Kramers ions and have rigorously doubly-degenerate microstates (Kramers doublets, KDs) in all symmetries in the absence of a magnetic field; non-Kramers ions require higher symmetry environments to have degenerate ground states in zero-field and therefore have the prerequisite bistable ground state to act as SMMs.

In 2010, SMM behaviour was observed for a monometallic 3d complex for the first time in the high-spin Fell complex $\mathrm{K}\left[\mathrm{Fe}\left(\mathrm{tpa}^{\mathrm{Mes}}\right)\right] \quad$ (tpaMes $\quad=$ mesityl-substituted tris(pyrrolylmethyl)amine; Figure 1). ${ }^{15}$ For monometallic $3 d$ SMMs, which are characterised by unusually large single-ion anisotropy, the magnetic states responsible for the energy barrier may be labelled by $M_{S}$ or $M_{J}$, depending on the details of the electronic structure; ${ }^{16}$ both first and second order spinorbit coupling effects can contribute to the splitting of magnetic microstates for these molecules.

\subsection{Other SMMs and Related Systems}

Other avenues explored with a view to improving SMM performance have included mixed $3 \mathrm{~d}$ and $4 \mathrm{f}$ clusters, and radical ligands bridging $3 \mathrm{~d}$ and/or $4 \mathrm{f}$ metal ions, both with the intention of increasing the total spin and manipulating the magnetic relaxation processes to achieve larger $U_{\text {eff }}$ barriers. ${ }^{17}$ More detailed overviews of the main SMM families are discussed in separate sections below. SMMs have also been reported based on the $5 f$ actinide elements, but their magnetic properties have not yet surpassed those of $4 \mathrm{f}$ complexes. ${ }^{18}$ 
Outside SMMs, there are alternative molecular strategies being investigated as potential data storage or switchable materials, but these will not be discussed in detail here. Such systems include spin-crossover, valence tautomerism (see eibc2785), light-activated, and nuclear-spin addressable compounds, as well as systems with long spin-coherence times which can be employed for Quantum Information Processing (QIP). ${ }^{19-23}$ Polymetallic toroidal magnets, which have non-classical chiral magnetic states, represent another class of addressable molecules. ${ }^{24,25}$

\section{MEASUREMENTS AND MECHANISMS}

\subsection{Magnetometry}

SMMs are characterised principally by the timescale it takes for an out-of-equilibrium magnetisation to return to equilibrium; this is known as the relaxation time $(\tau)$, or its reciprocal the relaxation rate, as shown in Equation 2, where $M_{0}$ is the initial magnetisation and $M_{e q}$ is the equilibrium magnetisation (the half-life is related to the relaxation rate as $\left.t_{1 / 2}=\tau \ln 2\right) .{ }^{1}$ The performance of SMMs are compared using two broad types of measurements - those that measure relaxation rates and those that measure a magnetic memory effect - but both are subject to external conditions such as temperature and magnetic field, and the latter is also history-dependent.

Equation 2: $M(t)=M_{e q}+\left(M_{0}-M_{e q}\right) e^{-t / \tau}$

The most fundamental demonstration of magnetic memory is the existence of magnetic hysteresis. ${ }^{1}$ A magnetic hysteresis experiment measures the net magnetisation as a function of external magnetic field during a continuous field-sweep, and assesses the ability of a material to show different magnetic moments depending on its history. Measurements are performed at fixed temperatures by applying a magnetic field $\left(+H_{\text {sat }}\right)$ until the magnetisation is saturated $\left(M_{\text {sat }}\right)$, then measuring the magnetic moment as the external field is reduced to $-H_{\text {sat }}$ and then increased to $+H_{\text {sat }}$ (Figure 3). An open hysteresis loop shows a deviation between the two sweep directions. The highest temperature for which open hysteresis is present is defined as the hysteresis blocking temperature $T_{H}$, but note that this is dependent upon sweep rate. ${ }^{26,27}$ Hysteresis loops are also defined by the remanent magnetisation $\left(M_{R}\right.$, magnetic moment at zero field) and the coercive field $\left(H_{C}\right.$, external field required to reach zero magnetisation). For some SMMs, "butterfly-shaped" or "waist-restricted" hysteresis loops are commonly observed, where the loop collapses considerably around zero-field (i.e. $H_{C} \sim 0$ ); ${ }^{28}$ this is because there is rapid quantum tunnelling of the magnetisation (QTM) between the ground states as they approach degeneracy (see section 2.2.2).

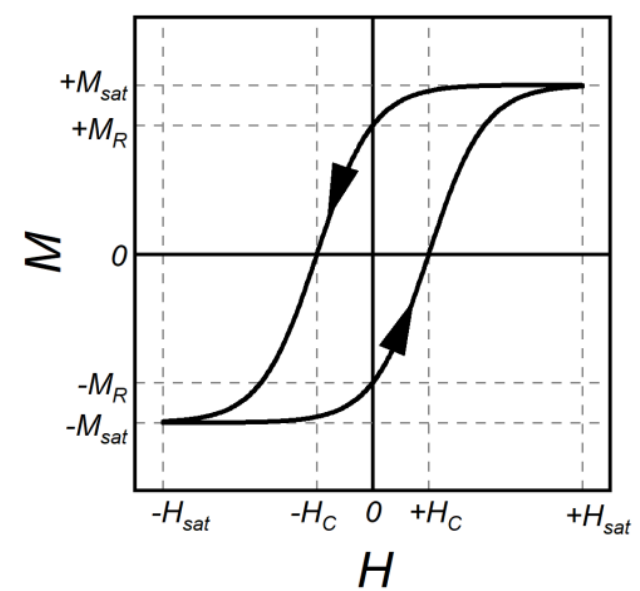

Figure 3. Magnetic hysteresis loop showing saturating field $\left(H_{\text {sat }}\right)$, coercive field $\left(H_{C}\right)$ and remanent magnetisation $\left(M_{R}\right)$.

Magnetic memory can also be quantified with a temperaturesweep measurement: the separation of zero-field cooled and field cooled (ZFC/FC) magnetic susceptibility. ${ }^{1}$ In the ZFC experiment, the sample is cooled to base temperature in zero external field, which ensures equal population of the two ground states (i.e. zero magnetisation). A small magnetic field is then applied and the magnetic susceptibility is measured upon warming at a fixed rate. During heating the sample equilibrates slowly due to the energy barrier for magnetisation reversal, but at some temperature there is sufficient thermal energy to overcome the $U_{\text {eff }}$ barrier and the sample reaches equilibrium $\left(T_{\text {irrev }}\right)$, which traditionally should coincide with the peak in the ZFC susceptibility $\left(T_{Z F C}\right) ;^{1}$ note that the relaxation dynamics in Ln SMMs are sufficiently complicated that this is not always the case. ${ }^{29}$ The FC experiment involves measuring magnetic susceptibility upon cooling in the same magnetic field as used to measure the ZFC trace; cooling in the presence of a magnetic field should, in theory, record the equilibrium susceptibility: however, this is not always the case, especially for Ln SMMs, and the FC data often deviate from the ZFC data and true equilibrium at $T_{\text {irrev. }}{ }^{29}$

Similar to field-swept dynamic measurements, $T_{\text {irrev }}$ and $T_{\text {ZFC }}$ are highly-dependent on sweep rate and the applied magnetic field. ${ }^{29}$ It is especially challenging to compare $T_{\text {ZFC }}$ values from the literature, as quite often temperature sweep rates are not reported. Temperature-sweep measurements also feature another difficulty: many high-performance SMMs are reactive in atmosphere and so samples are often sealed under vacuum in borosilicate or quartz ampoules, or other bulky containers, for magnetic measurements. These additional components have their own heat capacity which insulate the sample from the cryostat and thus generates uncertainty on the true sample temperature. Hence there may be a lag in the sample temperature in time-dependent temperature sweeps, in addition to slow magnetic dynamics, further complicating analysis.

It is important to note, however, that memory effects in SMMs such as hysteresis or ZFC/FC separation arise due to slow magnetic relaxation. Unlike traditional ferromagnets where 
there is a magnetic phase change below the Curie temperature, SMMs are zero-dimensional without long-range order. Hence, the memory effects are simply products of the temperatureand field-dependent relaxation rates and the measurement regime. In this sense, SMMs are far more like superparamagnets than like ferromagnets. ${ }^{1}$ Therefore, measurement of the underlying relaxation rates are critical to characterisation of SMMs.

In recent years, there has been debate over the quantification of SMM performance, because of the dependence of $T_{H}, T_{\text {irrev }}$ and $T_{\text {ZFC }}$ on measurement conditions. ${ }^{30}$ As SMM performance continues to improve, there is strong justification to define a "100 s blocking temperature" $\left(T_{100 s}\right)$, which is the temperature at which the relaxation time $\tau=100 \mathrm{~s}$, as a standard measure for SMM comparison. ${ }^{1,31}$ While the choice of $100 \mathrm{~s}$ is arbitrary, it is not skewed by experimental conditions. It has only become a viable parameter in the past few years, as more SMMs reach $\tau>100 \mathrm{~s}$

Magnetic relaxation in SMMs can be measured by two routes: direct current $(D C)$ and alternating current $(A C)$ techniques. ${ }^{1}$ The return of magnetisation from out-of-equilibrium towards equilibrium generally decays in an exponential fashion, Equation 2. Hence, the magnetic relaxation at a fixed temperature can be measured simply by magnetising the sample with a DC field, switching the field off rapidly, and then measuring the magnetisation decay as a function of time. The field does not have to be switched to zero, and in-fact can be non-zero, hence the field-dependence of relaxation rates can also be measured. DC techniques are usually suited when relaxation times are slow ( $c a . \tau>1 \mathrm{~s}$ ), but instrumental limitations on field ramp rate may put a lower limit on the accessible timescales (typically $\tau>10 \mathrm{~s}$ ). Such techniques are employed for many high performance SMMs to extract relaxation times at low temperatures. ${ }^{27,31-35}$

However, given the relaxation rates of SMMs are often much faster than detectable with DC methods at easily accessible temperatures (liquid $\mathrm{He}$ ), the most common technique to measure magnetic relaxation is AC susceptibility, most commonly applicable for $10^{-5}<\tau<1 \mathrm{~s}$, with the exact range depending upon the accessible frequencies of the instrument. ${ }^{1}$ AC susceptibility measures the ability of the sample to equilibrate in an oscillating magnetic field as a function of temperature and frequency. ${ }^{36}$ If relaxation is fast, the magnetisation can keep up with the oscillating field and the magnetisation is in-phase with the field. If relaxation is slow, then there is an out-of-phase response, which peaks when $1 / \tau$ $=\omega$, where $\omega$ is the angular frequency of the AC field. AC measurements can also be performed in a non-zero DC field, and thus can also be used to measure the field dependence of relaxation.

\subsection{SMM Relaxation Mechanisms}

The temperature- and field-dependence of the magnetic relaxation provide important insights into the mechanisms of relaxation occurring in SMMs. ${ }^{37}$ The relaxation rate profile of a typical high-performance SMM is presented in Figure 4 in two forms; the first is the natural logarithm of relaxation time vs. inverse temperature, and the second is a $\log _{10}-\log _{10}$ plot of relaxation rate $v s$. temperature. High-performance Ln SMMs often exhibit multiple different relaxation mechanisms, where the overall relaxation rate is simply the sum, and each mechanism tends to dominate in different temperature regimes; here we provide a characteristic example of a Ln SMM with three different regimes.

\subsubsection{Orbach Relaxation}

At the highest temperatures, the rate is exponentially dependent on temperature owing to relaxation via the Orbach mechanism. ${ }^{38}$ This is the over-barrier relaxation process which we have discussed for $\mathrm{Mn}_{12}$ and $\left[\mathrm{N}\left({ }^{\mathrm{B} B u}\right)_{4}\right]\left[\mathrm{Tb}(\mathrm{Pc})_{2}\right] \mathrm{SMMs}$, and is governed by an Arrhenius-type law, Equation 3. The natural logarithm representation is employed because an exponential temperature dependence is linear and thus $U_{\text {eff }}$ can simply be determined from the slope and $\tau_{0}$ from the $y$-intercept.

Equation 3: $\tau_{\text {orbach }^{-1}}=\tau_{0}{ }^{-1} \exp \left(-U_{\text {eff }} / k_{B} T\right)$

The Orbach mechanism involves absorption or emission of single vibrational quanta (phonons) to move between electronic microstates $\left(M_{S}\right.$ or $\left.M_{\jmath}\right) .{ }^{38}$ Phonons are quantised lattice vibrations which distort the molecular geometry and
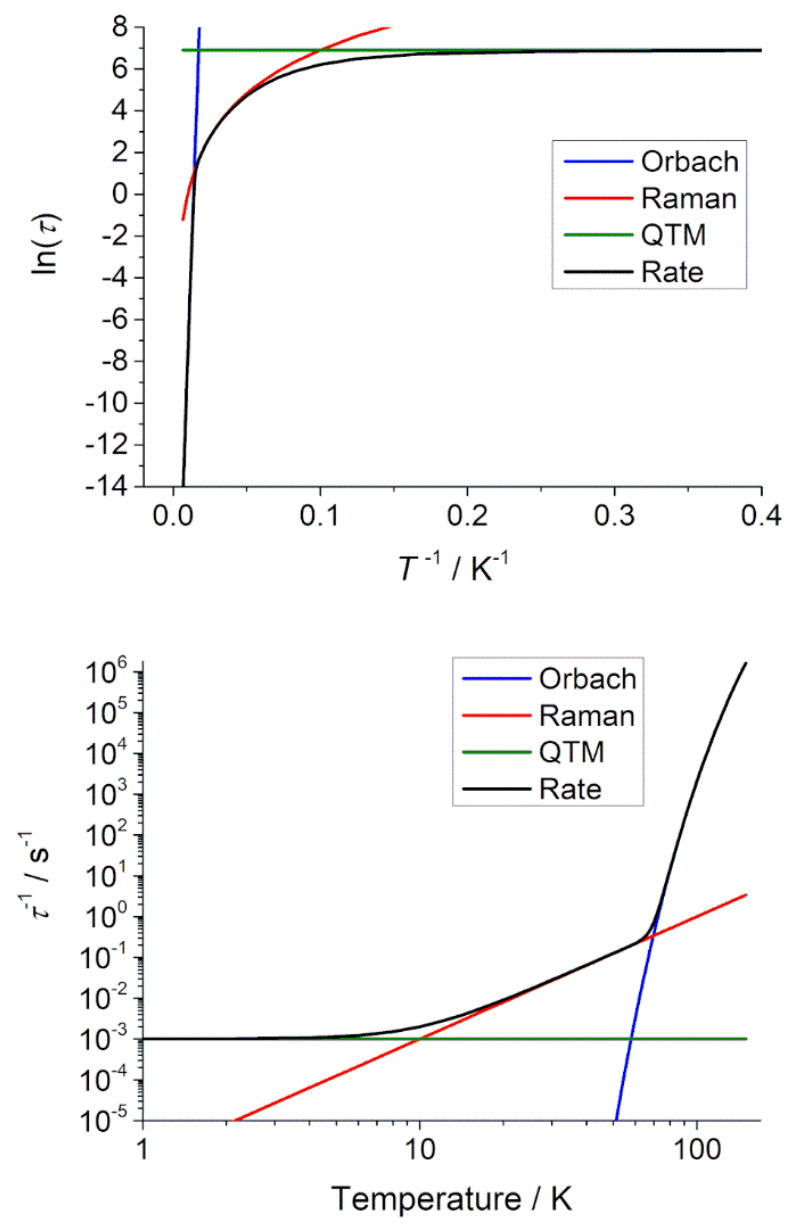

Figure 4. Generic relaxation profiles for an SMM: (top) the traditional representation with the linear Orbach regime 
plotted as the natural logarithm of relaxation time $\tau$ vs inverse temperature, $T^{-1}$; (below) $\log _{10}-\log _{10}$ plot of $\tau^{1}$ vs $T$ which clearly separates out the three relaxation regimes. Simulation parameters: $U_{\text {eff }}=2000 \mathrm{~K}, \tau_{0}=10^{-12} \mathrm{~s}, C=10^{-6} \mathrm{~s}^{-1}, n=3$ and $\tau_{\text {QTM }}$ $=1000 \mathrm{~s}$.

modulate the energies and wavefunctions of the electronic states. ${ }^{14}$ The molecule overcomes the $U_{\text {eff }}$ barrier via successive excitations followed by successive emissions (Figure 5); it should be noted that most spin-phonon excitations are followed by immediate de-excitations resulting in significant spin motion on either side of the barrier. ${ }^{1}$

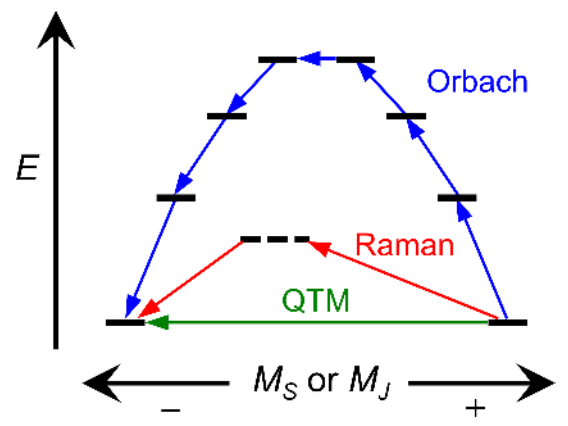

Figure 5. Relaxation processes in a zero-field SMM showing over-barrier Orbach relaxation, through-barrier quantum tunnelling of the magnetisation (QTM) and two-phonon Raman relaxation via a virtual excited state.

\subsubsection{Quantum Tunnelling of Magnetisation}

At the lowest temperatures, many SMMs reach a nearly temperature-independent relaxation rate: this is known as quantum tunnelling of magnetisation (QTM) which occurs between the degenerate ground states (Figure 5). In 1996, the first observation of macroscopic quantum tunnelling steps was observed in both polycrystalline and single crystal magnetometry studies, uncovering detailed understanding of the relaxation mechanisms in SMMs. ${ }^{39,40}$ While the rate is practically independent of temperature, it is highly fielddependent owing to the requirement of degeneracy of the ground states, hence the rate is often well-described by $\tau_{Q T M}{ }^{-1}$ $=B_{1} /\left(1+B_{2} H^{2}\right): 1,41$ here $B_{1}$ and $B_{2}$ are empirical parameters. This mechanism allows the SMM to bypass the $U_{\text {eff }}$ barrier to magnetisation reversal and is therefore no longer dependent upon spin-phonon coupling. In some cases, thermally-assisted (TA)-QTM can occur between degenerate excited states after spin-phonon excitation, and thus TA-QTM shows a temperature-dependence similar to the Orbach mechanism.

In molecules with fast QTM, a static magnetic field may be applied to quench this relaxation process and observe any other slow relaxation processes present. ${ }^{42}$ Molecules that only display slow relaxation in the presence of an applied field are denoted as field-induced SMMs, and are of rather limited utility for data storage applications.

QTM between KDs is a formally forbidden relaxation process that can become allowed through hyperfine and dipolar interactions. $^{30}$ To limit hyperfine interactions, the most apparent nuclear spin to focus on is the metal ion itself. Cador and co-workers have reported several studies looking into the effects of samples enriched with nuclear spin-free ${ }^{164} \mathrm{Dy} .{ }^{43-45}$ These studies show a non-negligible influence of the hyperfine coupling, which merits this as an important factor in SMM design. Nevertheless, some studies have also shown that effective control of the CF can be just as important, and excellent SMM performance can be established for SMMs with naturally abundant Dy. ${ }^{46}$ The strategy for removing hyperfine interactions can also extend to ligated atoms; many organic molecules contain a high number of hydrogen and nitrogen atoms, which all contribute to hyperfine coupling. While the influence of spin-free ligands is well understood for QIP coherence time studies, these hyperfine interactions have been rarely studied in SMMs. ${ }^{47-49}$

Dipolar interactions between neighbouring molecules can also enable fast QTM. There are numerous examples where hysteresis is improved for SMMs when diluted in a diamagnetic matrix, such as an isostructural analogue or frozen solution. . $^{4647}$ The relaxation rate profile often reveals magnetically diluted systems to have at least an order of magnitude slower QTM rates compared to pure samples, where some are only

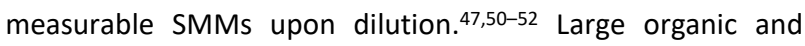
inorganic ligands have also been employed to increase intermolecular separation; these include polyoxometalatebased molecules, which have been heavily studied for their SMM and spin coherence properties (see eibc0185.pub2). ${ }^{53-57}$

\subsubsection{Raman Relaxation}

The third relaxation mechanism discussed here often dominates in an intermediate temperature range between Orbach and QTM, and is known as Raman relaxation. The Raman mechanism is a two-phonon process involving simultaneous absorption and emission of a pair of phonons which also allows the molecules to bypass the $U_{\text {eff }}$ barrier by mixing the ground states with an excited state in a concerted process (Figure 5 ); ${ }^{1}$ note that no intermediate state is occupied during the transition, unlike the Orbach process which occurs via a real intermediate state. This results in a power law dependence on temperature (Equation 4 and Figure 4), which appears linear when plotted on a $\log _{10}-\log _{10}$ plot.

$$
\text { Equation 4: } \quad \tau_{\text {Raman }^{-1}}=C T^{n}
$$

\subsubsection{Other Relaxation Mechanisms}

In the presence of an applied magnetic field, other relaxation pathways can exist, most notably direct relaxation between the non-degenerate ground states (degeneracy removed by the magnetic field) by absorption of a single phonon of appropriate energy ( $\tau^{1} \propto T H^{m}, m=2$ for non-Kramers ions or Kramers ions with hyperfine interactions and $m=4$ for Kramers ions), ${ }^{14,37,38}$ or a second-order Raman process $\left(\tau^{1} \propto T^{n} H^{2}\right) .{ }^{58}$

Measurements such as those discussed here aim to observe the inherent relaxation rate of the SMM due to spin-phonon coupling, which overall is often called spin-lattice relaxation; here the lattice is the environment which hosts the phonons 
that couple to the spin (this could be the crystal lattice, but could also be an amorphous environment). However, the lattice exists within an external environment (the "bath") which may consist of other crystallites, a restraining medium, the sample container, etc., which are then in contact with the cryostat. In some cases, the concentration of spins may be large, or the dimension of the lattice large, so that the phonons involved in relaxation are not able to reach the edge of the lattice and equilibrate with the bath. In this case the lattice is in effect "heated" and the measured relaxation rates now correspond to the lattice-bath rate instead of the spin-lattice rate. ${ }^{37}$ This is referred to as a phonon bottleneck and the measured latticebath relaxation rates will be slower than the expected spinlattice rates. ${ }^{59}$

\subsection{Complementary Characterisation}

Along with quantification of SMM performance, much research has been focussed on understanding the electronic states involved in the different relaxation mechanisms. From an experimental point of view, techniques which directly probe the relevant crystal field states include inelastic neutron scattering (INS, see eibc0294), electron paramagnetic resonance (EPR, see eibc0310), far-infrared and luminescence spectroscopies (see eibc2068). ${ }^{42}$ The applicability of each technique is dependent upon the type of SMM being studied, e.g. luminescence spectroscopy is particularly useful for $\mathrm{Ln}$ SMMs (see eibc2068). Molecules with low nuclear absorption cross sections or that can be easily deuterated are well-suited to INS spectroscopy; the successive spin excitations in the $\mathrm{Mn}_{12}$ Orbach relaxation mechanism have been mapped with INS.60 Several Ln SMMs have also been investigated with INS and are compiled in the review by Dunstan et al.61 EPR holds a particularly special place in SMM history, because the ZFS in $\mathrm{Mn}_{12}$ was identified with EPR before it was discovered to be an SMM. ${ }^{62}$

From a theoretical perspective, $a b$ initio calculations have proved vital in recent years for the interpretation of SMM properties. ${ }^{63}$ Such calculations, especially for Ln SMMs, can often be performed using a complete active-space selfconsistent field spin-orbit (CASSCF-SO) approach, where the contracted $4 \mathrm{f}$ orbitals provide a sufficient description of the multiconfigurational electronic states (see eibc0379). Novel SMM publications are now regularly supported by $a b$ initio calculations as validation of the CF states responsible for the experimentally-determined $U_{\text {eff }}$ barrier.

\section{POLYMETALLIC 3d SINGLE-MOLECULE MAGNETS}

Polymetallic transition metal clusters were the original systems where SMM properties were observed. As such, most of the early research focussed on $3 \mathrm{~d}$ polymetallic synthesis even after the discovery of monometallic Ln SMMs in 2003. $\left[\mathrm{Mn}_{12} \mathrm{O}_{12}\left(\mathrm{O}_{2} \mathrm{CCH}_{3}\right)_{16}\left(\mathrm{H}_{2} \mathrm{O}\right)_{4}\right]$ is a highly adaptable motif, with over 60 reported analogues arising from variation of the bridging ligands and solvent molecules; ${ }^{64}$ these have been studied in detail along with other $\mathrm{Mn}^{\text {III }}$ clusters via magnetometry, INS and EPR spectroscopy.
$\mathrm{Mn}^{\text {III }}$ oxo-bridged complexes were a keen focus due to the clear understanding of anisotropy arising from the individual ions, which occurs due to Jahn-Teller distortions from the uneven occupation of the $e_{g}$ orbitals in octahedral coordination environments. ${ }^{64}$ However, the performance of the archetypal $\mathrm{Mn}_{12}$ cluster (with $U_{\text {eff }}=49 \mathrm{~cm}^{-1}$ ) was usually greater than the novel complexes which were isolated. ${ }^{42}$ To date, the largest energy barrier for a $\mathrm{Mn}$ cluster (in fact for any $3 \mathrm{~d}$ metal cluster) is $U_{\text {eff }}=60 \mathrm{~cm}^{-1}$ for $\left[\mathrm{Mn}_{6} \mathrm{O}_{2}(\mathrm{Et}-\mathrm{sao})_{6}\left\{\mathrm{O}_{2} \mathrm{CPh}(\mathrm{Me})_{2}\right\}_{2}(\mathrm{EtOH})_{6}\right]$ ( $\mathrm{saOH}_{2}=$ salicylaldoxime), which was reported in 2007.65

SMM clusters have been expanded to a host of $3 d, 4 d$ and $5 d$ metals including $\mathrm{Ni}, \mathrm{Co}, \mathrm{V}, \mathrm{Fe}, \mathrm{Re}, \mathrm{Ru}$ and mixed d-block complexes. ${ }^{66,67}$ Some noteworthy and well-studied examples include $\mathrm{Fe}_{8}\left(\left\{\left[\mathrm{Fe}_{8} \mathrm{O}_{2}(\mathrm{OH})_{12}(\operatorname{tacn})_{6}\right] \mathrm{Br}_{7} \cdot \mathrm{H}_{2} \mathrm{O}\right\}\left[\mathrm{Br} \cdot 8 \mathrm{H}_{2} \mathrm{O}\right]\right.$, tacn $=$ 1,4,7-triazacyclononane) and $\mathrm{Fe}_{4}\left(\left[\mathrm{Fe}_{4}(\mathrm{OMe})_{6}(\mathrm{dpm})_{6}\right] \mathrm{dpm}=\right.$ 2,2,6,6-tetramethylheptane-3,5-dionate) (Figure 6).68,69 These investigations have included INS, high field EPR and Mössbauer spectroscopies, micro-SQUID magnetometry and surface studies testing the response to a range of stimuli. ${ }^{70-74} \mathrm{The} \mathrm{Fe}_{4}$ molecule has proved to be a robust manifold for detailed investigations into the capability for ligand functionalisation with surface binding peripheral groups.
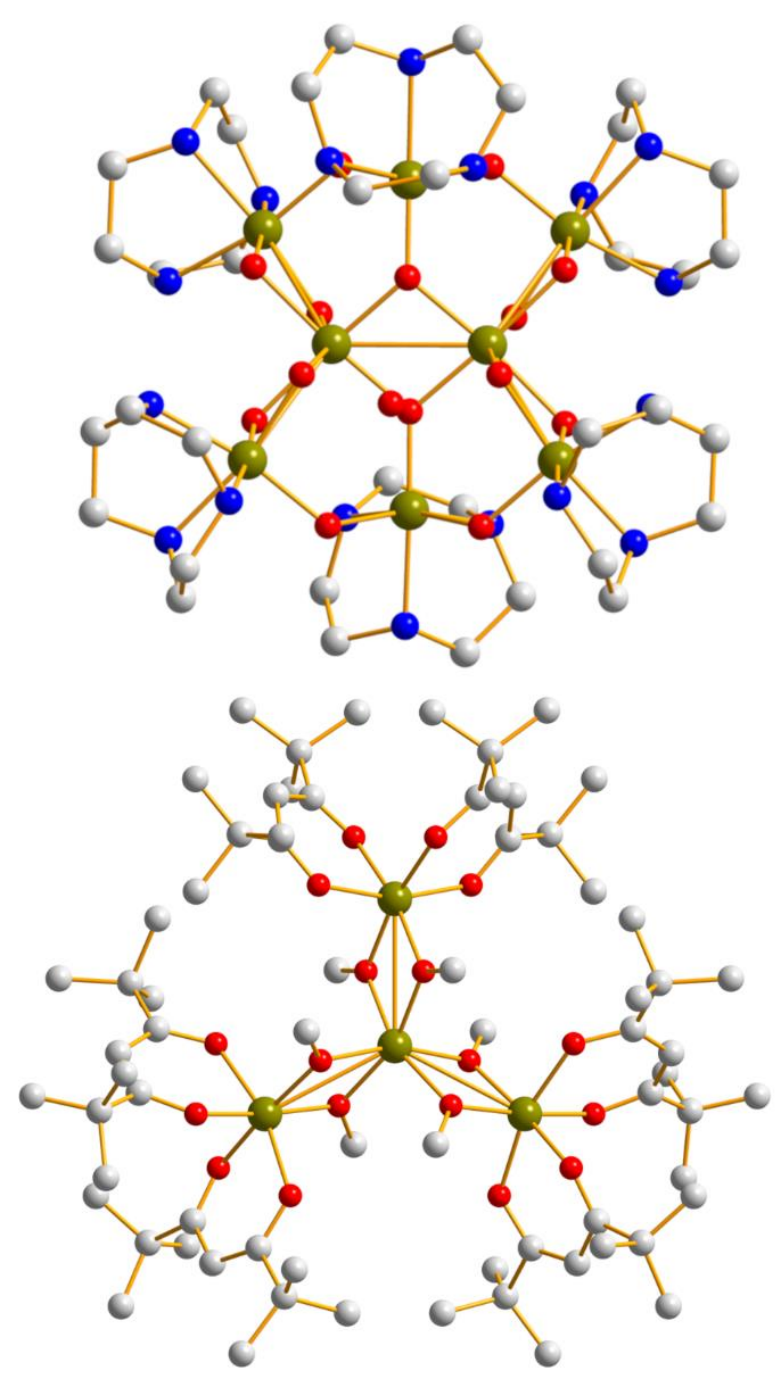
Figure 6. Polymetallic 3d SMMs (hydrogen atoms omitted for clarity): (top) $\left[\mathrm{Fe}_{8} \mathrm{O}_{2}(\mathrm{OH})_{12}(\operatorname{tacn})_{6}\right]^{8-} \quad($ tacn $=1,4,7-$ triazacyclononane), (bottom) $\left[\mathrm{Fe}_{4}(\mathrm{OMe})_{6}(\mathrm{dpm})_{6}\right](\mathrm{dpm}=$ 2,2,6,6-tetramethylheptane-3,5-dionate). Colour code: iron (ochre), oxygen (red), nitrogen (blue), carbon (grey).

Parallel to the focus on anisotropy, many studies sought to maximise the total ground state spin of the molecule by generating larger supramolecular clusters. This proved challenging, with reports over several years expanding from $\left[\mathrm{Fe}_{19}\right.$ (metheidi) $\left.{ }_{10}(\mathrm{OH})_{14}(\mathrm{O})_{6}\left(\mathrm{H}_{2} \mathrm{O}\right)_{12}\right] \mathrm{NO}_{3}$ (metheidi = $\left.\left\{\mathrm{CH}_{3} \mathrm{COOH}\right)_{2}(\mathrm{PrOH}) \mathrm{N}\right\}$, with $\mathrm{S}=33 / 2$ in $2000,{ }^{7}$ to $\left[\mathrm{Mn}_{25} \mathrm{O}_{18}(\mathrm{OH})_{2}\left(\mathrm{~N}_{3}\right)_{12}(\mathrm{pdm})_{6}(\mathrm{pdmH})_{6}\right] \mathrm{Cl}_{2}$ with $\mathrm{S}=51 / 2$, and up to $\mathrm{S}=83 / 2$ for $\left[\mathrm{Mn}^{1{ }^{1 \prime \prime}}{ }_{12} \mathrm{Mn}_{7}{ }_{7}\left(\mu_{4}-\mathrm{O}\right)_{8}\left(\mu_{3}, \eta^{1}-\mathrm{N}_{3}\right)_{8}(\mathrm{HL})_{12}(\mathrm{MeCN})_{6}\right] \mathrm{Cl}_{2}$ $\left(\mathrm{H}_{3} \mathrm{~L}=\right.$ 2,6-bis(hydroxy- methyl)-4-methylphenol)) in 2006.8,75 In terms of SMM performance, $\mathrm{Fe}_{19}$ and $\mathrm{Mn}_{25}$ exhibited $U_{\text {eff }}<15$ $\mathrm{cm}^{-1}$, whilst $\mathrm{Mn}_{19}$ showed no discernible energy barrier. In more recent years giant spin systems of $S=45,60$ and $S=91$ have been reported. ${ }^{5,9,10} \quad\left[\mathrm{Ni}_{21} \mathrm{Gd}_{20}(\mathrm{OH})_{24}(\mathrm{IDA})_{21}\right.$ $\left.(\mathrm{DPGA})_{6}\left(\mathrm{C}_{2} \mathrm{O}_{4}\right)_{3}\left(\mathrm{NO}_{3}\right)_{6}\left(\mathrm{CH}_{3} \mathrm{COO}\right)_{3}\left(\mathrm{H}_{2} \mathrm{O}\right)_{12}\right] \mathrm{Br}_{5}\left(\mathrm{NO}_{3}\right)_{4} \quad\left(\mathrm{IDAH}_{2}=\right.$ iminodiacetic acid and $\mathrm{DPGAH}_{2}=$ diphenylglycolic acid), reported in 2018, holds the current record for total spin in a single molecule with $S=91$, yet exhibits a negligible energy barrier to magnetisation reversal..$^{5}$ The maximisation of total spin leads to increased difficulty in controlling the orientation and interactions of the metal ions present within a molecule, resulting in an inverse relationship between anisotropy and spin, such that $U_{\text {eff }}$ is largely independent of $S .{ }^{6,76}$

\section{MONOMETALLIC $4 \mathrm{f}$ SINGLE-MOLECULE MAGNETS}

\subsection{Discovery and Design Criteria}

The discovery of monometallic SMMs was ground-breaking, not initially for their improved magnetic blocking temperatures, but for the significant improvement on the measured energy barrier to reversal of magnetisation. ${ }^{11,12}$ The first monometallic $\mathrm{SMM},\left[\mathrm{N}\left({ }^{\mathrm{B} B u}\right)_{4}\right]\left[\mathrm{Tb}(\mathrm{Pc})_{2}\right]$, reported by Ishikawa and co-workers in 2003, displays peaks in the out-of-phase AC susceptibility up to $40 \mathrm{~K}$ and $U_{\text {eff }}=230 \mathrm{~cm}^{-1}$; significantly larger than the standing record for polymetallic 3d SMMs (monometallic 3d SMMs only achieved a comparable energy barrier of $226 \mathrm{~cm}^{-1}$ a decade later, in 2013, see below). ${ }^{77}$ The noticeable improvement in $U_{\text {eff }}$ heralded a wave of research. ${ }^{17,78}$

For $4 \mathrm{f}$ SMMs, the magnetic states that give rise to slow relaxation are the CF states from the ground ${ }^{2 S+1} L_{\text {J }}$ electronic term. ${ }^{37}$ However, large CF splitting does not ensure stabilisation of a highly magnetic ground state on its own. If one can readily describe and understand how to stabilise specific $M_{\text {J }}$ projections, then one can engineer molecules to optimise the $U_{\text {eff }}$ barrier. ${ }^{79}$ The composition of the CF states and competing relaxation processes between states of opposite magnetisation must also be considered so they can be slowed down or quenched. The birth of monometallic $4 \mathrm{f}$ SMMs therefore shifted the focus in the field to controlling local coordination geometries of single $\mathrm{Ln}^{\text {III }}$ ions. ${ }^{11}$
Owing to the high pseudo-symmetry of the archetypal Ln SMM $\left[\mathrm{N}\left({ }^{\mathrm{B} B u}\right)_{4}\right]\left[\mathrm{Tb}(\mathrm{Pc})_{2}\right]$, which was of particular importance for the non-Kramers Tb"II, symmetry was closely considered for its impact on Orbach relaxation. ${ }^{29} \mathrm{CF}$ theory describes how molecular symmetry allows mixing of different $M_{\text {J }}$ states; ${ }^{80}$ when $M_{\text {J }}$ states are mixed, the transition probability between those states is increased and can hence reduce the effective $U_{\text {eff }}$ barrier. For the L $\mathrm{n}^{\text {III }}$ series, assuming no mixing of higher energy spin-orbit terms, the large orbital angular momentum requires up to $27 \mathrm{CF}$ parameters to appropriately describe the electronic states. ${ }^{80}$ Since the electronic Hamiltonian (and therefore the CF Hamiltonian) must be invariant under symmetry operations of the molecular point group, high symmetry environments require fewer CF parameters and therefore reduce mixing of $M_{J}$ states. In perfectly axial symmetry $\left(C_{\infty v}\right.$ or $\left.D_{\infty h}\right)$, none of the $M_{J}$ states are mixed, which by coincidence also occurs for $D_{4 d}$ symmetry (embodied by perfect square antiprismatic environments). However, any distortions from perfect $D_{4 d}$ symmetry (including atoms beyond the first coordination sphere) invalidates this rule and mixing is allowed. ${ }^{12}$

The original method of targeting improved $U_{\text {eff }}$ for $\left[\mathrm{Tb}(\mathrm{PcR})_{2}\right]^{n}$ derivatives was through the functionalisation of the Pc ligand, exploring various charge states $n$ and substituted $R$ groups to alter the electron density of the ligand and increase the symmetry of the coordination environment. ${ }^{81-85}$ This approach yielded energy barriers up to $653 \mathrm{~cm}^{-1}$ and $T_{H}=30 \mathrm{~K}$ (200 Oe.s 1 sweep rate) reported in 2017 for $\left[\mathrm{Tb}(\mathrm{Pc})\left\{\mathrm{Pc}\left[\mathrm{N}\left(\mathrm{C}_{4} \mathrm{H}_{9}\right)_{2}\right]_{8}\right\}\right]$ (Figure 7). ${ }^{86}$

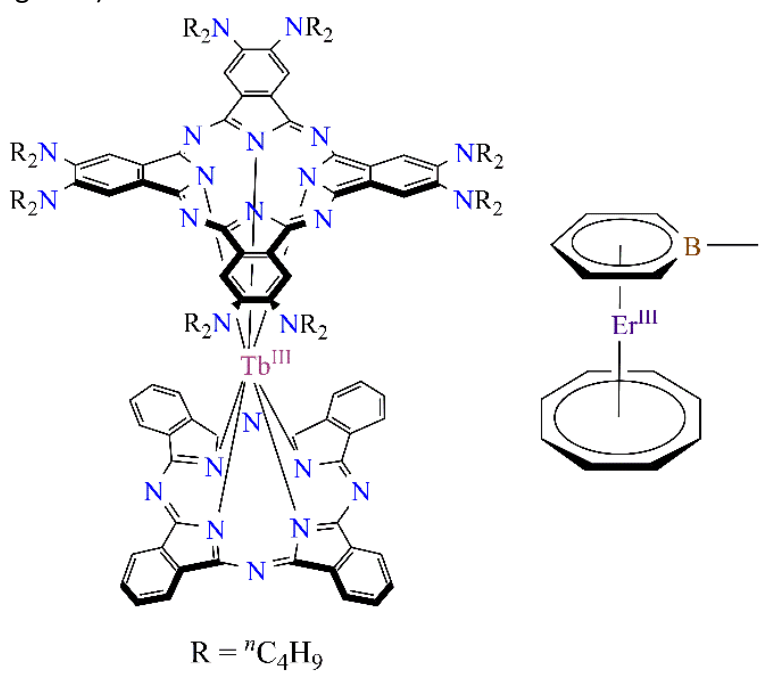

Figure 7. Selected $4 \mathrm{f} S M M s$ mentioned in text: (left) $\left[\mathrm{Tb}(\mathrm{Pc})\left\{\mathrm{Pc}\left[\mathrm{N}\left(\mathrm{C}_{4} \mathrm{H}_{9}\right)_{2}\right]_{8}\right\}\right]$, (right) $\left[\mathrm{Er}(\mathrm{COT})\left(\mathrm{C}_{5} \mathrm{H}_{5} \mathrm{BMe}\right)\right]$.

Er'II SMMs were targeted in high symmetry environments, ${ }^{87-93}$ with a focus on organometallic complexes with functionalised and unsubstituted $\mathrm{COT}^{2-}\left(\mathrm{COT}^{2-}=\right.$ cyclooctatetraenide $)$ and $\mathrm{Cp}$ $\left(\mathrm{Cp}^{-}=\right.$cyclopentadienyl) ligands, along with bulky amine donors. ${ }^{94}$ Homo- and hetero-leptic complexes have attempted to maximise $U_{\text {eff }}$ with the current record of $300 \mathrm{~cm}^{1}$ for $\left[\mathrm{Er}(\mathrm{COT})\left(\mathrm{C}_{5} \mathrm{H}_{5} \mathrm{BMe}\right)\right] \quad\left(\mathrm{C}_{5} \mathrm{H}_{5} \mathrm{BMe}=1\right.$-methyl-boratabenzene; Figure 7), reported in 2016. ${ }^{91}$ 
Symmetry alone is not sufficient to predict SMM properties. In 2011, Rinehart and Long highlighted design criteria to stabilise highly magnetic $\left|M_{\jmath}\right|$ states (and destabilise low $\left|M_{\jmath}\right|$ states) for various $\mathrm{Ln}^{\mathrm{III}}$ ions. ${ }^{79}$ This work builds on the analytical derivation of aspherical $4 \mathrm{f}$ electron density distributions of the pure ionic $M_{J}$ states for each Ln"' by Sievers in 1982 (Figure 8). ${ }^{95}$ The $\mathrm{Ln}^{\text {III }}$ series splits into those where the maximal $\left|M_{\jmath}\right|$ projection has prolate (elongated) spheroid electron density (e.g. Er, Tm, Yb) or oblate (squashed) spheroid electron density (e.g. Tb, Dy, Ho). The strategy for ions with oblate spheroidal densities in their large $\left|M_{\jmath}\right|$ states is to place charge on a single axis to stabilise the large $\left|M_{\jmath}\right|$ and destabilise low $\left|M_{J}\right|$ states; the inverse logic applies for prolate spheroids, where equatorial coordination of anions is targeted. An axial/equatorial donor is defined by ligand position that forms an average zenith angle less/greater than the magic angle of $54.7^{\circ}$ as measured between the ligand, metal and pseudo-symmetry axis. ${ }^{29}$

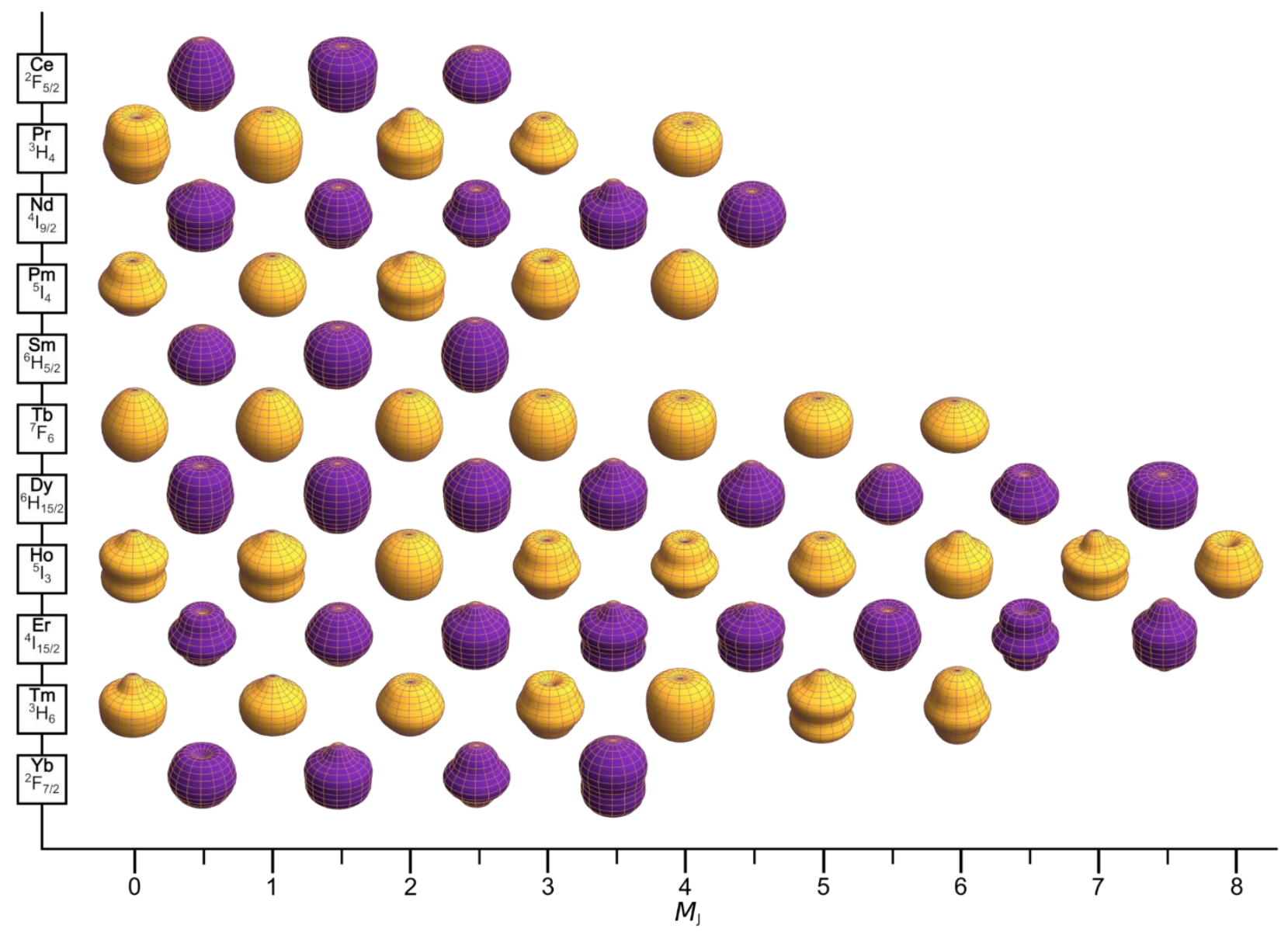

Figure 8. Illustration of the aspherical electron densities corresponding to the various $\left|M_{J}\right|$ projection of the $\operatorname{Ln}^{\text {III }}$ ions..$^{95,96}$

In 2011, the record Dy'll SMM Orbach barrier was $234 \mathrm{~cm}^{-1}$ from $\left[\mathrm{Dy}(\mathrm{sal})\left(\mathrm{NO}_{3}\right)(\mathrm{MeOH}) \mathrm{Zn}(\mathrm{L}) \mathrm{Br}\right]$ (sal = salicylaldehyde and $\mathrm{H}_{2} \mathrm{~L}=$ 6,6'-(1E,1'E)-(2,2-dimethylpropane-1,3-diyl)bis(azan-1-yl-1ylidene)bis(methan-1-yl-1-ylidene)bis(2-methoxyphenol); Figure 9). ${ }^{97}$ This record was broken repeatedly after publication of the design criteria by Rinehart and Long directed researchers to target axial crystal fields. ${ }^{79}$ This guidance was reinforced by calculations for a theoretical $\{\mathrm{Dy}-\mathrm{O}\}^{+}$fragment, validating that highly axial geometries generate high Orbach barriers to magnetisation reversal for Dy'll. ${ }^{98}$ Fortuitously, Dy"l' has a monotonic trend from oblate to prolate electron density distributions in its $M_{\jmath}$ states (Figure 8), allowing an axial CF to sequentially order the $M_{\jmath}$ states from most magnetic $\left(M_{\jmath}=\right.$ $\pm 15 / 2$ ) to least magnetic $\left(M_{\jmath}= \pm 1 / 2\right)$, creating a double-well potential. ${ }^{79}$ This ordering encourages relaxation via higher excited states and allowed Dy'll SMMs to surpass other Ln'II SMMs. ${ }^{27,32}$

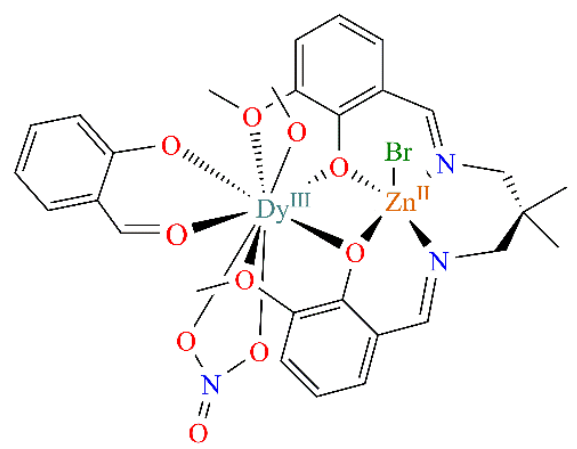

Figure 9. The Dy SMM [Dy(sal)(NO 3$)(\mathrm{MeOH}) \mathrm{Zn}(\mathrm{L}) \mathrm{Br}]$. 


\subsection{Axial Molecules with Point-Like-Charge Donors}

These design criteria led to the exploration of a range of hard oxo-donor ligands, to generate Dy"l' complexes containing phosphine oxides, alkoxides and aryloxides. ${ }^{17,99-101}$ As many of these ligands are monodentate donors and unlikely to stop further coordination at the L $\mathrm{n}^{\mathrm{III}}$ centre, a range of weakly coordinating donors were employed at the equatorial positions to stabilise the overall, highly anisotropic CF. In 2013, the record $U_{\text {eff }}$ barrier for Dy $y^{\text {III } S M M s}$ was increased to $305 \mathrm{~cm}^{-1}$ for $\left[\mathrm{Zn} \mathrm{n}_{2} \mathrm{Dy}(\mathrm{L})_{2}(\mathrm{MeOH})\right] \mathrm{NO}_{3}$, where $\mathrm{L}$ is the tripodal ligand $2,2^{\prime}, 2^{\prime \prime}$ (((nitrilotris(ethane-2,1-diyl))-tris(azanediyl))-tris(methylene))tris-(4-bromophenol). ${ }^{102}$ The resultant coordination sphere is a distorted pentagonal bipyramidal environment with the two deprotonated phenoxide donors forming a $168.6(2)^{\circ}$ angle, defining the axial environment. The equatorial coordination is also occupied by phenoxide donors; however, these bridge to $\mathrm{Zn}$ " cations, polarising the electron density and reducing their donor strength at the Dy"l' centre. The stabilisation of the ground $M_{J}= \pm 15 / 2$ state was validated by CASSCF calculations with the first excited state at $290 \mathrm{~cm}^{-1}$ in good agreement with the experimentally determined energy barrier.

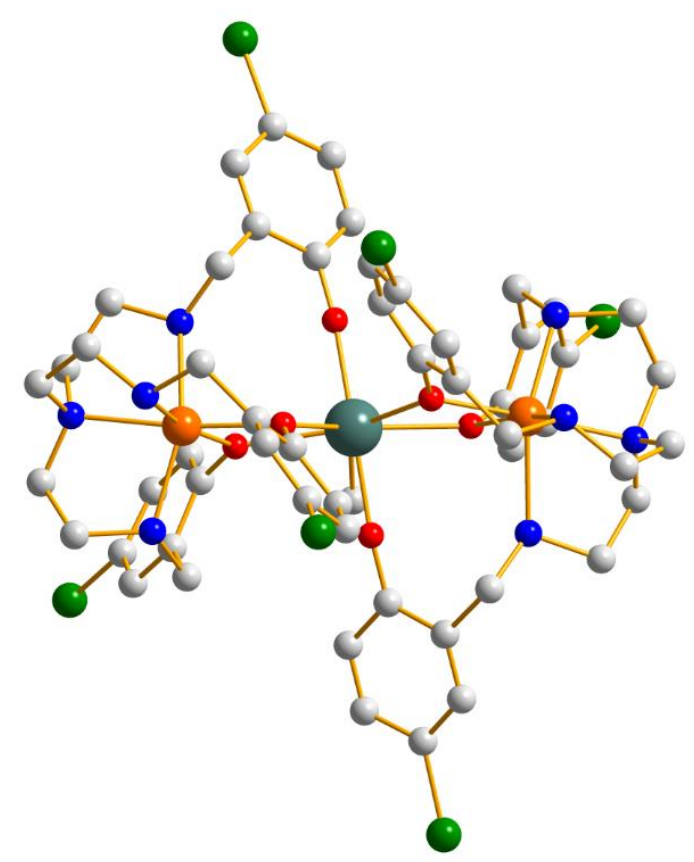

Figure 10. The Dy SMM with phenoxide donors, $\left[\mathrm{Zn}_{2} \mathrm{Dy}(\mathrm{L})_{2}(\mathrm{MeOH}) \mathrm{NO}_{3}\right.$ (hydrogen atoms omitted for clarity). Colour code: dysprosium (teal), zinc (orange), bromine (green), oxygen (red), nitrogen (blue), carbon (grey).

In 2016 the bis-methanediide complex [K(18-crown6) $\left.(\mathrm{THF})_{2}\right]\left[\mathrm{Dy}\left(\mathrm{BIPM}^{\mathrm{TMS}}\right)_{2}\right]-\left(\right.$ where BIPM ${ }^{\mathrm{TMS}}=\left\{\mathrm{C}\left(\mathrm{PPh}_{2} \mathrm{NSiMe}_{3}\right)_{2}\right\}^{2-}$, Figure 11) claimed the record $U_{\text {eff }}$ with a barrier of $565 \mathrm{~cm}^{-1}$. Two formally $\mathrm{C}^{2-}$ donors at $176.6(2)^{\circ}$ generate a strong axial $\mathrm{CF}$ with weakly coordinating equatorial nitrogen donors. ${ }^{103}$ Interestingly, although the crystal structure reveals a single molecule in the asymmetric unit, the AC susceptibility data reveals two distinct processes which are simultaneously fitted with two energy barriers. The two barriers of 501 and $565 \mathrm{~cm}^{-1}$ were both higher than any previously reported in the literature and were assigned to competing relaxation via the close lying third and fourth excited states.

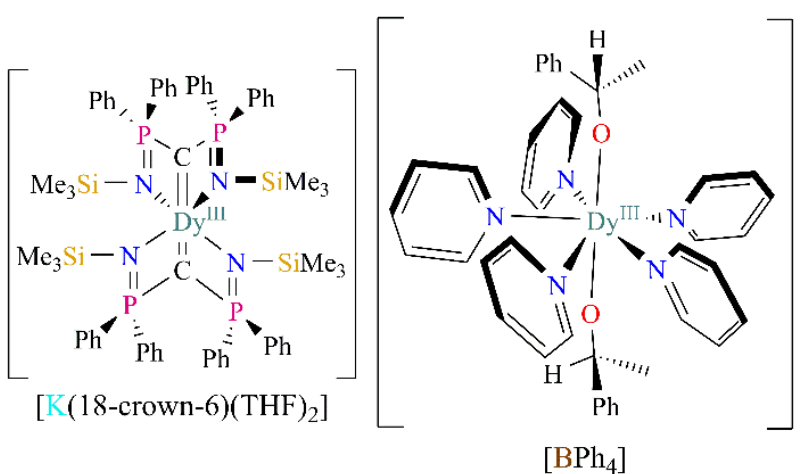

Figure 11. Monometallic Dy SMMs with axial point-charge donors: (left) $\left[\mathrm{K}\left(18\right.\right.$-crown-6)(THF) $\left.{ }_{2}\right]\left[\mathrm{Dy}\left(\mathrm{BIPM}^{\mathrm{TMS}}\right)_{2}\right]$, (right) $\left[\mathrm{Dy}\{(\mathrm{S})-\mathrm{OCHPhMe}\}_{2}(\mathrm{py})_{5}\right]\left[\mathrm{BPh}_{4}\right]$.

Despite not claiming the record, early 2016 saw the publication of several SMMs with similar $U_{\text {eff }}$ values reported in quick succession. The molecules $\left[\mathrm{Dy}\left(\mathrm{Cy}_{3} \mathrm{PO}\right)_{2}\left(\mathrm{H}_{2} \mathrm{O}\right)_{5}\right] \mathrm{Br}_{3}$ and [Dy $\left.\left.\left\{{ }^{\mathrm{t}} \mathrm{BuPO}\left(\mathrm{NH}^{\mathrm{P} P r}\right)_{2}\right\}_{2}\left(\mathrm{H}_{2} \mathrm{O}\right)_{5}\right]\right]_{3}$ revealed barriers of $377 \mathrm{~cm}^{-1}$ and $452 \mathrm{~cm}^{-1}\left(511 \mathrm{~cm}^{-1}\right.$ when diluted into an $Y$ matrix), respectively, with structures utilising axial neutral phosphine oxide donors. ${ }^{100,104}$ These complexes were the first monometallic Dy ${ }^{\prime \prime \prime}$ SMMs with pentagonal bipyramidal coordination geometries and homoleptic neutral equatorial ligands.

The standing SMM $U_{\text {eff }}$ record was again broken in 2016 with the first energy barrier reported over $1000 \mathrm{~K}\left(695 \mathrm{~cm}^{1}\right)$ by Tong and co-workers. ${ }^{26}$ Utilising a bis-phenoxide hexadentate ligand bbpen $\left(\mathrm{H}_{2}\right.$ bbpen $=\mathrm{N}, \mathrm{N}$-bis (2-hydroxy-benzyl)-N,N-bis(2methylpyridyl)ethylenediamine), an energy barrier of $712 \mathrm{~cm}^{-1}$ (1024 K) was reported for [Dy(bbpen)Br] where the equatorial environment is occupied by four neutral nitrogen donors and a single bromide anion. The strong axial phenoxide donors, combined with the weak neutral amines and diffuse electron density of the bromide, results in very large anisotropy. Comparison to the previous phosphine oxide ligands suggests the origin of larger anisotropy is the harder Lewis acidic nature of the phenoxide donor, resulting in reduced Dy-O bond lengths of 2.163(3) A from previous complexes with axial bonds over $2.2 \AA$. Thus, despite the axial O-Dy-O angle being $155.8(2)^{\circ}$ and an anion in the equatorial plane, a large $U_{\text {eff }}$ barrier is still achieved.

This milestone was quickly surpassed by the enormous energy barrier of $1261 \mathrm{~cm}^{-1}(1815 \mathrm{~K})$ of $\left[\mathrm{Dy}\left(\mathrm{O}^{\mathrm{t}} \mathrm{Bu}\right)_{2}(\mathrm{py})_{5}\right]\left[\mathrm{BPh}_{4}\right]$ (py = pyridine; Figure 1), almost doubling the previous record..$^{99}$ Here, the isolation of a trans-bis-tert-butoxide-coordinated Dy"II ion stabilised by neutral equatorial pyridine ligands was reported as approaching the limit of CF splitting at Dy'II for a coordination complex. The neutral equatorial ligands combined with the hard tert-butoxide ligands is responsible for the large anisotropy.

Despite repeated breaking of record energy barriers, these SMMs did not show commensurate increases in blocking 
temperature as would be expected for a six-fold increase in $U_{\text {eff. }}$. This is of course dependent on the definition used for blocking temperature and since those reported in literature vary, it is difficult to directly compare "the blocking temperature" of these molecules. Nevertheless, [K(18-crown6)(THF) $\left.)_{2}\right]\left[\left\{\mathrm{Tb}\left[\mathrm{N}\left(\mathrm{SiMe}_{3}\right)_{2}\right]_{2}(\mathrm{THF})\right\}_{2}\left(\mu-\eta^{2}: \eta^{2}-\mathrm{N}_{2}\right)\right]$, with $T_{\text {ZFC, }}, T_{100 \text { s }}$ and $T_{H}$ all measured at $14 \mathrm{~K}$ (Figure 1 , see section 6.1) was usually considered to be the benchmark for magnetic memory. ${ }^{105}$ This radical dianionic dinitrogen-bridged complex from 2011, with an experimental energy barrier of $227 \mathrm{~cm}^{-1}$, was consistently better-performing than all the record-barrier SMMs discussed that were measured under a consistent sweep rate. Recently, a novel pentagonal bipyramidal chiral complex $\left[\mathrm{Dy}\{(\mathrm{S})-\mathrm{OCHPhMe}\}_{2}(\mathrm{py})_{5}\right]\left[\mathrm{BPh}_{4}\right]$ supported by non-covalent intramolecular interactions (Figure 11), shows $U_{\text {eff }}=1130(20)$ $\mathrm{cm}^{-1}, T_{\mathrm{ZFC}}=23 \mathrm{~K}$ and $T_{H}=22 \mathrm{~K}$ and boasts slower Raman and QTM regimes than the parent complex $\left[\mathrm{Dy}\left(\mathrm{O}^{\mathrm{t} B u}\right)_{2}(\mathrm{py})_{5}\right]\left[\mathrm{BPh}_{4}\right]^{106}$

Despite the concerted effort of the SMM research community, all Dy"l SMMs in 2016 with strong axial donors still possessed several equatorial ligands. The route to isolating a molecule without any equatorial coordination at a $\mathrm{Ln}^{\text {III }}$ ion was unclear, and due to the unpredictability of literature blocking temperatures it was speculative whether such a complex would enable higher blocking temperatures. One synthetic direction was to design bulky ligands to support a two-coordinate linear geometry using nitrogen or phosphorous donor-atoms. ${ }^{107}$ This research gained traction following the isolation of near-linear $\mathrm{Ln}^{\text {II }}$ complexes and subsequent bent $\mathrm{Ln}{ }^{\mathrm{III}}$ molecules ( $\mathrm{Ln}=\mathrm{Sm}$, Tm, Yb). ${ }^{108,109}$ Despite these efforts, a two-coordinate Dy'II complex has not been isolated to date.

\subsection{Axial Molecules with Cp-Donors}

Aside from using monodentate ligands, cyclopentadienide (Cp) chemistry was known as a way to occupy more coordination sites of $\mathrm{Ln}^{\text {III }}$ ions and hence block equatorial ligand coordination, with careful design to exclude coordinating solvent or counter ions. ${ }^{110}$ For many years, several groups prepared a host of [ $\left[\mathrm{LCp}_{2} \mathrm{X}_{n}\right]$ ( $n=1$ or $2, \mathrm{X}=$ anionic ligand) SMMs, but were unable to inhibit equatorial ligand coordination (see eibc2032). ${ }^{84,111-113}$ These strategies also yielded several polymetallic complexes, ${ }^{50}$ where additional coordination sites were occupied by bridging ligands, including redox-active radical ligands. ${ }^{114,115}$

In 2017, a major breakthrough came with the synthesis of the first isolated lanthanide metallocenium cation viz. $\left[\mathrm{Dy}\left(\mathrm{Cp}^{\mathrm{ttt}}\right)_{2}\right]\left[\mathrm{B}\left(\mathrm{C}_{6} \mathrm{~F}_{5}\right)_{4}\right]\left(\mathrm{Cp}^{\mathrm{ttt}}=\mathrm{C}_{5} \mathrm{H}_{2} \mathrm{BBu}_{3}-1,2,4\right.$; Figure 1), reported in separate publications by Goodwin et al. ${ }^{32}$ and Guo et al. ${ }^{116,117}$ The successful isolation of a dysprosocenium cation was achieved via halide abstraction of a chloride-containing precursor using the silylium reagent $\left[\mathrm{H}\left(\mathrm{SiEt}_{3}\right)_{2}\right]\left[\mathrm{B}\left(\mathrm{C}_{6} \mathrm{~F}_{5}\right)_{4}\right]$, which also delivers the weakly-coordinating anion $\left.\left[\mathrm{B}_{(} \mathrm{C}_{6} \mathrm{~F}_{5}\right)_{4}\right]$. The absence of equatorial coordination increases $T_{100 \text { s }}$ to $53 \mathrm{~K}$, an increase of $39 \mathrm{~K}$ from [K(18-crown6)(THF) $\left.)_{2}\right]\left[\left\{\mathrm{Tb}\left[\mathrm{N}\left(\mathrm{SiMe}_{3}\right)_{2}\right]_{2}(\mathrm{THF})\right\}_{2}\left(\mu-\eta^{2}: \eta^{2}-\mathrm{N}_{2}\right)\right]$. However, $\left[\mathrm{Dy}\left(\mathrm{Cp}^{\mathrm{ttt}}\right)_{2}\right]\left[\mathrm{B}\left(\mathrm{C}_{6} \mathrm{~F}_{5}\right)_{4}\right]$ shows a $U_{\text {eff }}$ barrier of $1223 \mathrm{~cm}^{-1}$, ca.
$40 \mathrm{~cm}^{-1}$ smaller than the record set by $\left[\mathrm{Dy}\left(\mathrm{O}^{\mathrm{t}} \mathrm{Bu}\right)_{2}(\mathrm{py})_{5}\right][\mathrm{BPh} 4]$. Comparison of the relaxation rates between these two SMMs shows that $\left[\mathrm{Dy}\left(\mathrm{O}^{\mathrm{t}} \mathrm{Bu}\right)_{2}(\mathrm{py})_{5}\right]\left[\mathrm{BPh} \mathrm{BP}_{4}\right]$ relaxes $c a .200$ times faster at $60 \mathrm{~K}$ owing to a far more significant Raman relaxation regime compared to $\left[\mathrm{Dy}\left(\mathrm{Cp}^{\mathrm{ttt}}\right)_{2}\right]\left[\mathrm{B}\left(\mathrm{C}_{6} \mathrm{~F}_{5}\right)_{4}\right]$. This comparison marks an important milestone in the literature: that $U_{\text {eff }}$ barriers could be designed to be so large that optimisation of other relaxation mechanisms must be a critically limiting step. A 2020 INS study on $\left[\mathrm{Dy}\left(\mathrm{Cp}^{\mathrm{ttt}}\right)_{2}\right]\left[\mathrm{B}\left(\mathrm{C}_{6} \mathrm{~F}_{5}\right)_{4}\right]$ suggests that the slow Raman relaxation is a result of a large energy gap between the ground $M_{\jmath}= \pm 15 / 2$ and first excited $M_{\jmath}= \pm 13 / 2$ states, a rigid first coordination sphere and weak intermolecular interactions, which limit the available phonons for Raman relaxation. ${ }^{58}$

Continued improvements in $U_{\text {eff }}$ have been achieved with other substituted dysprosocenium cations by varying $\mathrm{Cp}$ ring Rgroups. In 2018, five novel dysprosocenium cations were reported in separate reports by Gould et al. ${ }^{31}$ and Guo et al.;27 the latter report of $\left[\mathrm{Dy}\left(\mathrm{C}_{5}{ }^{\mathrm{i}} \mathrm{Pr}_{5}\right)\left(\mathrm{C}_{5} \mathrm{Me}_{5}\right)\right]\left[\mathrm{B}\left(\mathrm{C}_{6} \mathrm{~F}_{5}\right)_{4}\right]$ (Figure 12) holds the current record $U_{\text {eff }}$ barrier of $1541 \mathrm{~cm}^{-1}$ and record blocking with $T_{Z F C}=54, T_{100 s}=65$ and $T_{H}=80 \mathrm{~K}$.
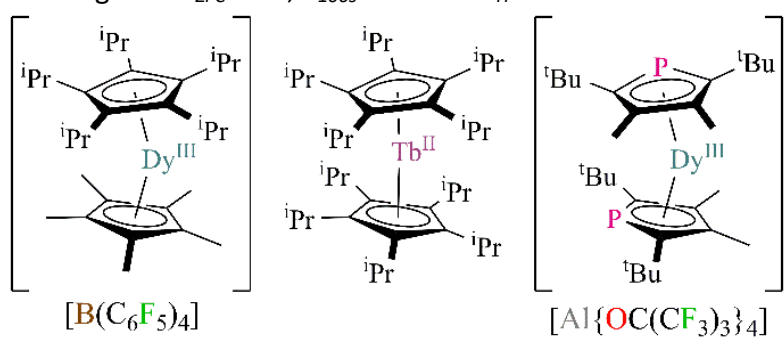

Figure 12. Evolved $\mathrm{Ln}$ metallocene-based SMMs: (left) $\left[\mathrm{Dy}\left(\mathrm{C}_{5}^{\mathrm{i}} \mathrm{Pr}_{5}\right)\left(\mathrm{C}_{5} \mathrm{Me}_{5}\right)\right]\left[\mathrm{B}\left(\mathrm{C}_{6} \mathrm{~F}_{5}\right)_{4}\right], \quad$ (centre) $\left[\mathrm{Tb}\left(\mathrm{C}_{5}{ }^{\mathrm{P} P \mathrm{P}_{5}}\right)_{2}\right], \quad$ (right) $\left[\mathrm{Dy}(\mathrm{Dtp})_{2}\right]\left[\mathrm{Al}\left\{\mathrm{OC}\left(\mathrm{CF}_{3}\right)_{3}\right\}_{4}\right]$.

There has been much recent research on the factors which have resulted in such marked improvement for dysprosocenium systems. State-of-the-art calculations have aimed to calculate the spin-phonon coupling and hence the relaxation rates. $32,106,118,119$ While varying in approach and complexity, the main aim is to identify structural factors contributing to relaxation dynamics, and determine if modification of ligand scaffolds could lead to improved SMM performance. Preliminary work on $\left[\mathrm{Dy}\left(\mathrm{Cp}^{\mathrm{ttt}}\right)_{2}\right]^{+}$by Goodwin et al. highlighted the influence of the ring $\mathrm{C}-\mathrm{H}$ vibrations at the unsubstituted 3,5protons of $\mathrm{Cp}^{\mathrm{ttt}}$ matching the energy gap from the ground to first excited $K D$, thereby contributing significantly to Orbach relaxation. ${ }^{32}$ Subsequent $C \mathrm{p}^{\mathrm{R}}$ variants that achieved higher blocking temperatures lacked these $\mathrm{C}-\mathrm{H}$ groups, providing some validation for this suggestion. ${ }^{27,31}$ Nevertheless, even with such vibrations absent, other important vibrations reveal themselves, placing more stringent criteria on future targets for enhanced performance. ${ }^{120}$

Evolution of the field has seen molecules related to dysprosocenium also prove to be among the best performing SMMs: a neutral Tb" complex being the best non-Dy SMM, $\left[\mathrm{Tb}\left(\mathrm{C}_{5}^{\mathrm{i}} \mathrm{Pr}_{5}\right)_{2}\right]$, has $U_{\text {eff }}=1205 \mathrm{~cm}^{-1}, T_{100 s}=52 \mathrm{~K}$ and $T_{\mathrm{H}}=55 \mathrm{~K}^{35}$

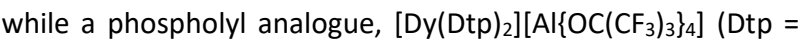


$\left.\mathrm{P}\left(\mathrm{C}^{\mathrm{t} B u C M e}\right)_{2}\right)$, has $U_{\text {eff }}=1223 \mathrm{~cm}^{-1}, \mathrm{~T}_{\mathrm{ZFC}}=25 \mathrm{~K}, T_{100 \mathrm{~s}}=23 \mathrm{~K}$ and $T_{H}=48 \mathrm{~K}$ (Figure 12)..$^{120}$

\section{MONOMETALLIC 3d SINGLE-MOLECULE MAGNETS}

Monometallic 3d SMMs are also possible, but instead of relying on large $S$, they must be designed to maximise magnetic anisotropy at the single-ion level like for $4 \mathrm{f}$ ions. ${ }^{16}$ The field of $3 d$ SMMs was outlined in a tutorial review by Craig and Murrie in 2015. ${ }^{16}$ For monometallic 3d SMMs the crystal field and spinorbit coupling effects can be of similar size, and so the microstates involved in SMM behaviour are not always easily labelled as $M_{S}$ or $M_{j}$; below we will outline the cases of dominant CF, dominant spin-orbit coupling and intermediate situations.

In the case of strong CF splitting and/or Jahn-Teller distortions, the degeneracy of the $3 \mathrm{~d}$ orbitals can be lost, thus quenching the orbital angular momentum resulting in a spin-only ground state (see eibc0118). ${ }^{16}$ In such cases in less than cubic symmetry, an $S>1 / 2$ ground state can experience ZFS (owing to second-order spin-orbit coupling where excited orbitallydegenerate states are mixed in) splitting the $M_{S}$ microstates: this is the case for the ions comprising "traditional" $3 d$ polymetallic SMMs. A good monometallic example is the tetrahedral Coll complex $\left(\mathrm{PPh}_{4}\right)_{2}\left[\mathrm{Co}(\mathrm{SPh})_{4}\right]$ with an $\mathrm{S}=3 / 2$ ground state with ZFS of $D=-74 \mathrm{~cm}^{-1}$ and $E \leq 0.01 \mathrm{~cm}^{-1}$, which displays slow relaxation with $U_{\text {eff }}=21 \mathrm{~cm}^{-1} .{ }^{121} \mathrm{In}$ an axial molecule, the energy of the first excited state is equal to $2 D$. It is common for monometallic SMMs to be reported with experimental barriers much smaller than $2 D$ or than the spectroscopically determined energy of the first excited state this has been attributed to the role of off-resonance relaxation processes, ${ }^{118}$ but may also be the result of incorrect fitting of the experimental data. Extraction of a $U_{\text {eff }}$ value by fitting only a few data points at low temperature leads to incorrect values; instead all relaxation rates should be comprehensively modelled. ${ }^{122,123}$

In the strong CF limit, mixing of excited states into the ground state via spin-orbit coupling is inversely proportional to the energy gap between the CF states, and so a smaller splitting of CF states leads to a larger splitting of $M_{s}$ states (larger $\left.D\right) .{ }^{124}$ The pseudo-tetrahedral Co"l complex $\left(\mathrm{HNEt}_{3}\right)_{2}\left[\mathrm{Co}\left\{\mathrm{C}_{6} \mathrm{H}_{4}\left(\mathrm{NSO}_{2} \mathrm{Me}\right)_{2}-\right.\right.$ $1,2\}_{2}$ ] (Figure 13), has a low energy excited state because of a strong ligand field and dominant axial distortion. ${ }^{123}$ This leads to a very large $D$ of $-115 \mathrm{~cm}^{-1}$ and slow relaxation with $U_{\text {eff }}=230$ $\mathrm{cm}^{-1}$. This molecule has such large anisotropy because of near orbital degeneracy $\left(d_{x y}\right.$ orbital is close in energy to the $d x^{2}-y^{2}$ and $\mathrm{dz}^{2}$ orbitals), such that it is on the border of having firstorder orbital angular momentum.

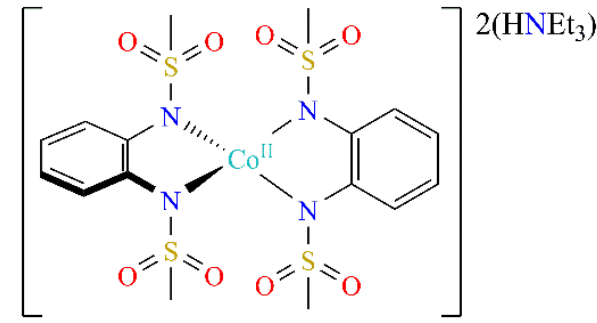

Figure 13. A monometallic Coll SMM $\left(\mathrm{HNEt}_{3}\right)_{2}\left[\mathrm{Co}\left\{\mathrm{C}_{6} \mathrm{H}_{4}\left(\mathrm{NSO}_{2} \mathrm{Me}\right)_{2}-1,2\right\}_{2}\right]$.

When $3 d$ orbital degeneracy is partially retained after the CF interactions, and there is an unequal electron population in degenerate orbitals that are related by rotational symmetry, unquenched orbital angular momentum can arise, but typically less than for the free ion. ${ }^{125}$ Such is the case for the first monometallic 3d SMM, K[Fe(tpaMes)], reported in 2010 by Freedman et al. (Figure 1). ${ }^{15}$ The high spin trigonal pyramidal

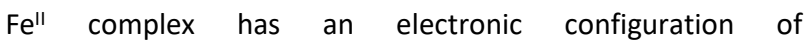
$(d x z, d y z)^{3}\left(d x y, d x^{2}-y^{2}\right)^{2}\left(d z^{2}\right)^{1}$; the unequal population of the $d_{x z}$ and $d_{y z}$ orbitals gives rise to orbital angular momentum and first-order spin-orbit coupling. ${ }^{126}$ However, like many monometallic 3d SMMs, it has facile QTM between the ground states in zero field, and so application of a magnetic field is required to observe slow relaxation with $U_{\text {eff }}=42 \mathrm{~cm}^{-1} .{ }^{15}$

Often in the literature, a spin-only model and $M_{S}$ labels are used for $3 d$ ions even in the presence of first-order orbital angular momentum; this is incorrect and misleading. Instead, states arising from $L$ and $S$ must be considered, ${ }^{125,126}$ as the states involved in slow relaxation arise from both spin-orbit and CF effects. A model of only the ground $J$ manifold (as used for $4 \mathrm{f}$ SMMs) may be appropriate if the CF is sufficiently weak compared to spin-orbit coupling and no excited states are populated in the temperature range investigated. ${ }^{77,122,127} \mathrm{In}$ this

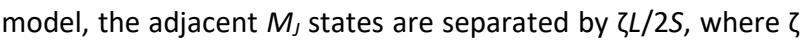
is the spin-orbit coupling constant for the free ion. ${ }^{77,122}$

Linear geometries have been particularly successful for $3 d$ monometallic SMMs because $\left(d x y, d x^{2}-y^{2}\right)$ and $(d x z, d y z)$ orbital degeneracies are retained in $\mathrm{D}_{\infty \mathrm{h}}$ and $\mathrm{C}_{\infty_{v}}$ symmetry. A twocoordinate $\mathrm{Fe}^{\mathrm{l}}$ complex, [K(2.2.2-cryptand) $]\left[\mathrm{Fe}\left\{\mathrm{C}\left(\mathrm{SiMe}_{3}\right)_{3}\right\}_{2}\right]$ (Figure 14) has an electronic configuration of $\left(\mathrm{dz}^{2}\right)^{2}\left(\mathrm{dx}^{2}-\right.$ $\left.y^{2}, d x y\right)^{3}(d x z, d y z)^{2}$, with the $3 d$ orbitals spread over only 5000 $\mathrm{cm}^{-1}$ due to the weak CF; this gives rise to almost unquenched orbital angular momentum and thus first-order spin-orbit coupling $(S=3 / 2$ and $L=2$ giving $J=7 / 2)$ and large anisotropy. ${ }^{77}$ The $M_{J}= \pm 7 / 2$ states are calculated to be stabilised by $210 \mathrm{~cm}^{-1}$ relative to $M_{J}= \pm 5 / 2$, and in the absence of an applied magnetic field this $\mathrm{Fel}^{\mathrm{l}}$ complex displays slow relaxation with $U_{\text {eff }}=226$ $\mathrm{cm}^{-1}$. The same orbital splitting can be obtained with a trigonal prismatic $\left(D_{3}\right)$ geometry, as demonstrated by the isolelectronic pseudo-clathrochelate Co" complex, [Co\{ $\mathrm{K}^{6}-N, N, N, N^{\prime}, N^{\prime}, N^{\prime}$ $\left.\left.\mathrm{PhB}\left[\mathrm{ONC}(\mathrm{Me}) \mathrm{C}_{3} \mathrm{~N}_{2} \mathrm{H}\right]_{3}\right\} \mathrm{Cl}\right]$. This complex has the lowest energy microstates separated by $220 \mathrm{~cm}^{-1}$ and held the record barrier for a Co SMM in 2015 with $U_{\text {eff }}=152 \mathrm{~cm}^{-1} .{ }^{122}$ 


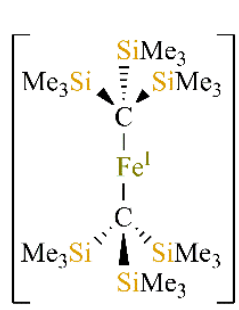

$[\mathrm{K}(2.2 .2$-cryptand $)]$

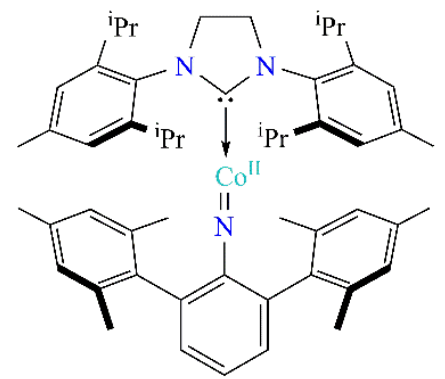

$$
\text { NapthO }
$$

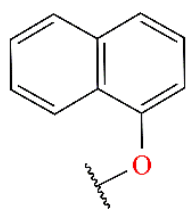

Figure 14. Linear monometallic 3d SMMs: (top left) [K(2.2.2cryptand)][Fe\{C(SiMe $\left.\left.)_{3}\right\}_{2}\right]$, (top right) $\left[\mathrm{Co}\left(\mathrm{NC}_{6} \mathrm{H}_{3} \mathrm{Mes}_{2}-\right.\right.$ $\left.2,6)\left\{\mathrm{C}\left[\mathrm{N}(\text { Dipp }) \mathrm{CH}_{2}\right]_{2}\right\}\right]$, (bottom) [Co $\left.\left\{\mathrm{C}\left(\mathrm{SiMe}_{2} \mathrm{ONapth}\right)_{3}\right\}_{2}\right]$.

In 2017 the record set by [K(2.2.2-cryptand)][Fe $\left.\left\{\mathrm{C}\left(\mathrm{SiMe}_{3}\right)_{3}\right\}_{2}\right]$ was broken with $U_{\text {eff }}=413 \mathrm{~cm}^{-1}$ for $\left[\mathrm{Co}\left(\mathrm{NC}_{6} \mathrm{H}_{3} \mathrm{Mes}_{2}-\right.\right.$ $\left.2,6)\left\{\mathrm{C}\left[\mathrm{N}(\text { Dipp }) \mathrm{CH}_{2}\right]_{2}\right\}\right]$ (Dipp $=\mathrm{C}_{6} \mathrm{H}_{3} \mathrm{Pr}_{2}-2,6 ;$ Mes $=\mathrm{C}_{6} \mathrm{H}_{2} \mathrm{Me}_{3}-$ 2,4,6; Figure 14). ${ }^{127}$ This linear complex has a short cobalt-imido double bond which maximises the cobalt anisotropy to stabilise the $M_{J}= \pm 7 / 2$ states $(S=3 / 2, L=2, J=7 / 2)$. Cobalt has a larger spin-orbit coupling constant than iron due to the larger effective nuclear charge, which is one reason Co" complexes are able to out-perform the Fel complex.122,128 The current-best $3 \mathrm{~d}$ $\mathrm{SMM}$ is a linear $\mathrm{Co}^{\prime \prime}$ complex, $\left[\mathrm{Co}\left\{\mathrm{C}\left(\mathrm{SiMe}_{2} \mathrm{ONapth}\right)_{3}\right\}_{2}\right]$ (Figure 14), with $U_{\text {eff }}=450 \mathrm{~cm}^{-1} .128$ A very weak $\mathrm{CF}$ results in an intermediate or "non-Aufbau" spin ground state, ( $\mathrm{dx}^{2}$ $\left.\mathrm{y}^{2}, \mathrm{dxy}\right)^{3}(\mathrm{dxz}, \mathrm{dyz})^{3}\left(\mathrm{dz}^{2}\right)^{1}$, which attains a maximum total angular momentum quantum number of $J=9 / 2(S=3 / 2, L=3)$.

Also of note are some Coll molecules that exhibit in-field SMM behaviour despite their easy-plane $(D>0)$ electronic structures stabilising $M_{S}= \pm 1 / 2.129,130$ In near-zero external field, selection rules implied by Kramers time reversal symmetry and van Vleck cancellation indicate that spin-phonon coupling cannot enable a direct transition between the two $M_{S}= \pm 1 / 2$ microstates, opening up opportunities for slow magnetic relaxation dependent on other processes, such as Raman relaxation or direct relaxation mediated by hyperfine coupling. ${ }^{129}$

\section{EXCHANGE-COUPLED SINGLE-MOLECULE MAGNETS}

\subsection{Monometallic-Radical SMMs}

Monometallic SMMs often have fast relaxation at zero field due to strong QTM in the ground doublet, accelerated by the presence of unfavourable mixing of $M_{\boldsymbol{J}}$ states (as mixed states are particularly sensitive to transverse magnetic fields) in low symmetry coordination environments. ${ }^{30}$ This results in butterfly-shaped hysteresis with small coercive fields, and in some cases slow relaxation can only be observed under an applied magnetic field to disrupt resonant QTM. ${ }^{16,28} \mathrm{~A}$ strategy to mitigate zero-field QTM is by magnetically coupling multiple spin centres, shifting the ground state degeneracy and resulting in a so-called exchange biasing of the QTM away from zero field. ${ }^{131}$

The $\left[\mathrm{Tb}(\mathrm{PcR})_{2}\right]^{n}$ derivatives show butterfly hysteresis for $n=-1$, +1 , but for some $n=0,-2$ complexes, the presence of an organic radical delocalised over the two Pc ligands opens the hysteresis loop and results in higher coercive fields. ${ }^{131}$ Such is the case for $\left[\mathrm{Tb}\left(\mathrm{Pc} \mathrm{R}_{8}\right)_{2}\right]^{n}(\mathrm{R}=$ isopropylidenedioxy), which shows closed waist-constricted hysteresis loops for $n=-1$ and +1 and open hysteresis with a coercive field of $0.16 \mathrm{~T}$ for $n=0.132$ The introduction of a radical spin coupled to a $\mathrm{Ln}^{\text {III }}$ metal centre can suppress QTM relaxation pathways, and in the case of Tbradical pairs the resulting complex is Kramers, which contributes to suppressing QTM in the ground KD. ${ }^{131}$

A host of monometallic SMMs with other organic radicals have been investigated following the breakthrough of the Lnphthalocyaninato radical complexes, but as yet none are as successful as SMMs. ${ }^{131}$ Lanthanide complexes have been investigated with nitronyl nitroxide (NIT), (2,2,6,6tetramethylpiperidin-1-yl)oxyl (TEMPO), triazinyl, phosphorous-centred and diborane radicals. ${ }^{131,133-135}$ Typically, weak coupling occurs between the Ln $4 f$ orbitals and the radical, yielding sufficient exchange coupling to break the ground state degeneracy, but often introducing new relaxation pathways. In contrast, 3d-radical complexes have stronger exchange coupling, the best example is a tetrakis-tripletcarbene complex $\left[\mathrm{Co}(\mathrm{NCO})_{2}\left(\mathrm{NC}_{5} \mathrm{H}_{4} \mathrm{CPh}-4\right)_{4}\right]$, which shows $U_{\text {eff }}=$ $130 \mathrm{~cm}^{-1}$ and $T_{H}=4.8 \mathrm{~K} .{ }^{136} \mathrm{~A} \mathrm{Co}{ }^{\prime \prime}-\mathrm{NIT}$ complex, $\left[\mathrm{Co}(\mathrm{L})_{2}\right]\left(\mathrm{NO}_{3}\right)_{2}(\mathrm{~L}$ $=$ 4-dimethyl-2,2-di(2-pyridyl)), is also of note for its multifunctionality, showing a small energy barrier under applied field and spin-crossover at higher temperatures. ${ }^{137}$

\subsection{Polymetallic 3d-4f and 4f-4f SMMs}

Mixed-metal systems can provide information on how weak exchange interactions can have beneficial effects on relaxation behaviour. ${ }^{42}$ Designing polymetallic $4 \mathrm{f}$ complexes and molecules which couple $3 \mathrm{~d}$ and $4 \mathrm{f}$ ions together has been an area of interest over several years. The first mixed $3 d-4 f$ metal $\mathrm{SMM},\left[\mathrm{Cu}(\mathrm{L}) \mathrm{Tb}(\mathrm{hfac})_{2}\right] \quad\left(\mathrm{H}_{3} \mathrm{~L}=1\right.$ - (2-hydroxybenzamido)-2-(2hydroxy-3-methoxy-benzylideneamino)-ethane, hfac = hexafluoroacetylacetonate), was reported in 2004 by Matsumoto and co-workers with $U_{\text {eff }}=15 \mathrm{~cm}^{-1} .{ }^{138}$ In the years since, detailed studies of $3 d-4 f$ variants have been explored, including systematic studies of families of $\mathrm{M}^{\prime \prime \prime}{ }_{2} \mathrm{Ln}^{\prime \prime \prime}{ }_{2}(\mathrm{M}=\mathrm{Co}, \mathrm{Cr}$ and $L n=G d, T b$ and Dy) molecules by Murray et al. ${ }^{139-141} \mathrm{In}$ 2015 , the largest barrier for a $3 d-4 f$ molecule was reported by the Tong research group, with $U_{\text {eff }}=416 \mathrm{~cm}^{-1}$ observed for an SMM with a $\mathrm{Co}_{2}$ Dy core. ${ }^{142}$

Purely $4 \mathrm{f}$ polymetallic SMMs have also revealed novel properties in molecular magnetism. There are examples of bimetallic, trimetallic and higher nuclearity Ln'II molecules, with different exchange motifs and pathways. ${ }^{143}$ One such group, the multidecker Tb"II pthalocyanates, have been 
comprehensively investigated, including addressability on surfaces. ${ }^{144-146}$

Noteworthy polymetallic $4 \mathrm{f}$ molecules include the clusters [Dy 5 O(O'Pr $\left.)_{13}\right]$ and $\left[\mathrm{Dy}_{4} \mathrm{~K}_{2} \mathrm{O}\left(\mathrm{O}^{\mathrm{t}} \mathrm{Bu}\right)_{12}\right]$ (Figure 15), which respectively show large barriers of $367 \mathrm{~cm}^{-1}$ and $480 \mathrm{~cm}^{-1}$ (the record for Dy SMMs in 2013), ${ }^{147}$ and the dimeric complex $\left[\mathrm{Dy}\left(\mathrm{C}_{5} \mathrm{Me}_{5}\right)_{2}\left\{\mu-\mathrm{CpFe}(\mathrm{CO})_{2}\right\}\right]_{2}$. The latter complex is bridged via carbonyl- linked diamagnetic $\{\mathrm{FeCp}\}$ units with a barrier of 662 $\mathrm{cm}^{-1}\left(50 \mathrm{~cm}^{-1}\right.$ short of the record in 2016), ${ }^{26}$ owing to the singleion properties of each Dy"ll.50 An endohedral fullerene Dy 2 ScN@ $\mathrm{C}_{80}-\mathrm{I}_{\mathrm{h}}$ from 2017 holds the current record barrier for a polymetallic $4 \mathrm{f}$ molecule, with $U_{\text {eff }}=1206 \mathrm{~cm}^{-1} .{ }^{148}$ Despite the significant barrier size, its magnetic memory effect is similar to $\left[\mathrm{Dy}\left(\mathrm{O}^{\mathrm{t}} \mathrm{Bu}\right)_{2}(\mathrm{py})_{5}\right]\left[\mathrm{BPh} \mathrm{B}_{4}\right]$, with $T_{H}=T_{Z F C}=7 \mathrm{~K}$ and $T_{100 \mathrm{~s}}=5 \mathrm{~K}$. Note that for these three molecules, and in fact most polymetallic $4 \mathrm{f}$ SMMs, the exchange interactions are so weak that the SMM property appears to arise solely from single-ion anisotropy with minimal positive influence from weak exchange interactions.

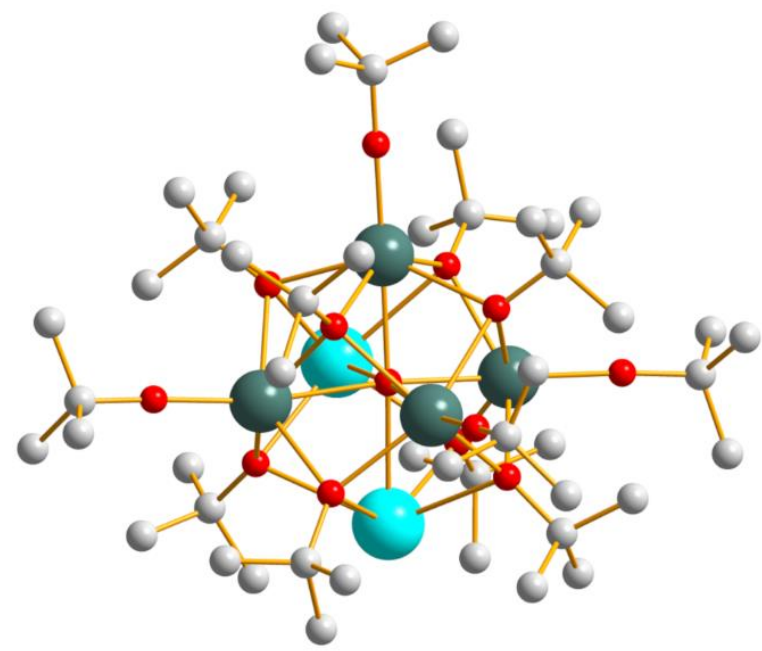

Figure 15. Crystal structure of polymetallic $4 f \mathrm{SMM}$, $\left[\mathrm{Dy}_{4} \mathrm{~K}_{2} \mathrm{O}\left(\mathrm{O}^{\mathrm{t}} \mathrm{Bu}\right)_{12}\right.$ ] (hydrogen atoms omitted for clarity). Colour code: dysprosium (teal), potassium (cyan), oxygen (red), carbon (grey).

\subsection{Bimetallic Radical-Bridged SMMs}

Along with synthetic targets focussed on achieving significant exchange coupling between metal ions, radical ligands have been implemented as bridges to mediate and enhance magnetic coupling. A good summary is provided in a 2015 review by Demir et al., highlighting a host of mono- and polymetallic 3d-radical and 4f-radical SMMs. ${ }^{131}$

A breakthrough in bimetallic radical-bridged SMMs occurred in 2011 with the synthesis of [K(18-crown6)] $\left[\left\{\mathrm{Ln}\left[\mathrm{N}\left(\mathrm{SiMe}_{3}\right)_{2}\right]_{2}(\mathrm{THF})\right\}_{2}\left(\mu-\eta^{2}: \eta^{2}-\mathrm{N}_{2}\right)\right](\mathrm{Ln}=\mathrm{Tb}, \mathrm{Dy}, \mathrm{Gd}, \mathrm{Ho}, \mathrm{Er}$; Figure 1), where the Tb analogue had record-breaking $T_{H}, T_{Z F C}$ and $T_{100 s}$ of $14 \mathrm{~K} .{ }^{105,149}$ The $\mathrm{Ln}$-radical exchange is very strong ( $J_{G d-r a d}=-27 \mathrm{~cm}^{-1},-2 J$ formalism) because of the diffuse radical spin on the compact $\mathrm{N}_{2}{ }^{3-}$ bridge and the radical existing in a $\pi^{*}$ orbital perpendicular to the $\mathrm{Ln}_{2} \mathrm{~N}_{2}$ plane, enabling good overlap with $4 \mathrm{f}$ orbitals. ${ }^{149} \mathrm{~A}$ computational model of the $\mathrm{Tb}^{\text {III }}$ complex indicates the doubly-degenerate exchange-coupled states contain mixtures of multiple Tb"II CF states because the exchange is the same order of magnitude as the CF splitting. ${ }^{150}$ The mixing of CF states causes relaxation to occur via TA-QTM in the first excited exchange-coupled doublet. The current state-of-the-art radical-coupled Ln SMM is [K(2.2.2cryptand) $]\left[\left\{\mathrm{Tb}\left(\mathrm{C}_{5} \mathrm{Me}_{4} \mathrm{H}\right)_{2}\right\}_{2}\left(\mu-\eta^{2}: \eta^{2}-\mathrm{N}_{2}\right)\right]$ (Figure 16), which has two experimental $U_{\text {eff }}$ values of $276 \mathrm{~cm}^{-1}$ and $564 \mathrm{~cm}^{-1}, T_{100 \mathrm{~s}}=$ $20 \mathrm{~K}, T_{H}=30 \mathrm{~K}$ and a large coercive field of $H_{C}=7.9 \mathrm{~T}$ at $10 \mathrm{~K} .{ }^{151}$ The higher axiality and low coordination number improves the performance relative to the original $\left[\left\{\mathrm{Tb}\left[\mathrm{N}\left(\mathrm{SiMe}_{3}\right)_{2}\right]_{2}(\mathrm{THF})\right\}_{2}(\mu-\right.$ $\left.\left.\eta^{2}: \eta^{2}-N_{2}\right)\right]^{-}$molecule. ${ }^{105}$ In each case of bimetallic $L n$ complexes bridged by $\mathrm{N}_{2}{ }^{3--}$ radicals, the Tb analogue outperforms the Dy variant. ${ }^{105,149,151}$
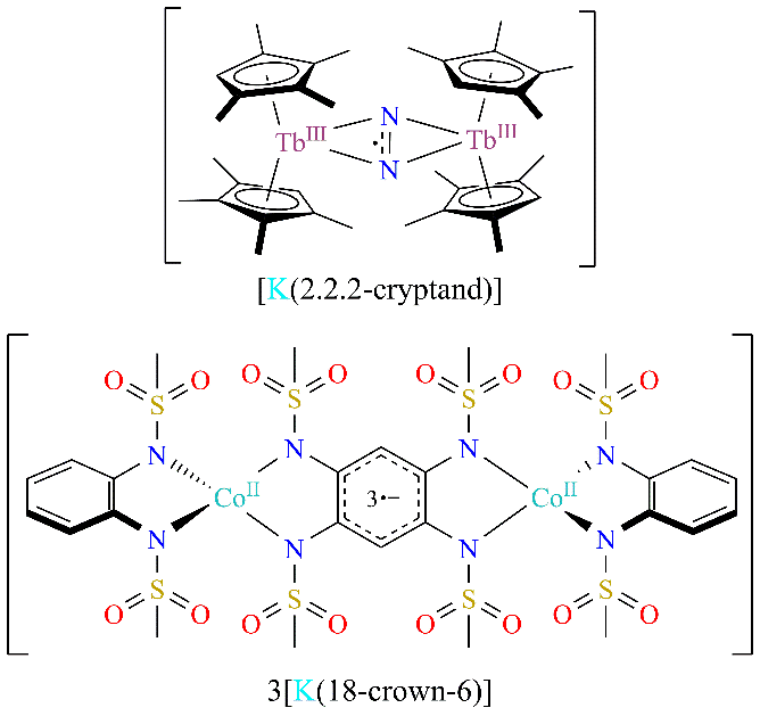

Figure 16. Radical-bridged bimetallic SMMs: (top) $[\mathrm{K}(2.2 .2$ cryptand)] $\left[\left\{\mathrm{Tb}\left(\mathrm{C}_{5} \mathrm{Me}_{4} \mathrm{H}\right)_{2}\right\}_{2}\left(\mu-\eta^{2}: \eta^{2}-\mathrm{N}_{2}\right)\right]$, (bottom) [K(18-crown6)] $\left[\left\{\mathrm{Co}\left[\mathrm{C}_{6} \mathrm{H}_{4}\left(\mathrm{NSO}_{2} \mathrm{Me}\right)_{2}-1,2\right]\right\}_{2}\left\{\mu-\eta^{2}: \eta^{2}-\mathrm{C}_{6} \mathrm{H}_{2}\left(\mathrm{NSO}_{2} \mathrm{Me}\right)_{4^{-}}\right.\right.$ $1,2,4,5\}]$

Redox-active ligands have also been used to bridge $3 d$ and $4 f$ ions, which imparts redox switchability to the SMM behaviour. ${ }^{131}$ In particular, reduction or oxidation to create a radical-bridged complex may quench QTM and switch on SMM behaviour in zero magnetic field. ${ }^{152,153} \mathrm{Ln}$ ions with redox active ligands have been reviewed by Hay and Boskovic in 2020. ${ }^{154}$ Since 2015, 3d bimetallic SMMs bridged by redox-active ligands have expanded from only two complexes, both with an azophenine or $\mathrm{N}$-indigo bridge, ${ }^{131}$ to include other benzosemiquinoid derivatives, ${ }^{155,156}$ tetrapyridophenazine, ${ }^{157}$ and air-stable complexes with bipyrimidine, ${ }^{158}$ and substituted tetrazines. ${ }^{159}$ The best dinuclear $3 \mathrm{~d}$-radical SMM is [K(18crown-6)][\{Co[C $\left.\left.\mathrm{C}_{6} \mathrm{H}_{4}\left(\mathrm{NSO}_{2} \mathrm{Me}\right)_{2}-1,2\right]\right\}_{2}\left\{\mu-\eta^{2}: \eta^{2}-\mathrm{C}_{6} \mathrm{H}_{2}\left(\mathrm{NSO}_{2} \mathrm{Me}\right)_{4^{-}}\right.$ $1,2,4,5\}$ ] (Figure 16) with $U_{\text {eff }}=183 \mathrm{~cm}^{-1}$ in zero field; here the radical bridge slows the relaxation at $18 \mathrm{~K}$ by a factor of 350 relative to the non-radical monometallic precursor (Figure 13). .159

An interesting example of radical-coupled SMMs are endofullerene systems with encapsulated $L n^{\prime \prime \prime}$ ions (see eibc2049). Like the $\left[\mathrm{Tb}(\mathrm{PcR})_{2}\right]^{n}$ derivatives, the fullerene surface can accommodate various oxidation states and facilitate exchange between the trapped Ln ions. ${ }^{160}$ The most 
noteworthy example is [Dy $\left.{ }_{2} @ \mathrm{C}_{80}\left(\mathrm{CH}_{2} \mathrm{Ph}\right)\right]$ from 2017 (Figure 17), where a single electron is hypothesised to be located in between two Dy'll ions (of formally +2.5 oxidation state), all held inside a fullerene cage. ${ }^{161}$ The strong interaction of $J_{D y, e}=-32$ $\mathrm{cm}^{-1}$ used in the modelling of the coupled energy spectrum reproduces the observed energy barrier of $613 \mathrm{~cm}^{-1}$, associated with the spin flip of one of the spin centres (Dy'll or radical). While not a remarkable barrier, the $T_{H}=21 \mathrm{~K}, T_{\text {ZFC }}=22 \mathrm{~K}$ and $T_{100 s}=18 \mathrm{~K}$ were records at the time and are significantly better than most SMMs with similar energy barriers.

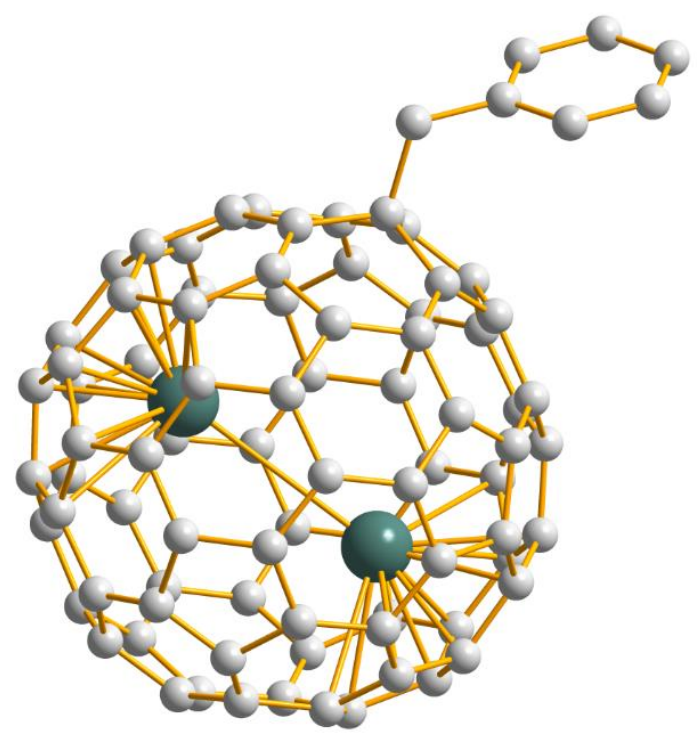

Figure 17. Crystal structure of endofullerene-encapsulated $4 \mathrm{f}$ radical SMM, [Dy $\left.@ \mathrm{C}_{80}\left(\mathrm{CH}_{2} \mathrm{Ph}\right)\right]$ (hydrogen atoms omitted for clarity). Colour code: dysprosium (teal), carbon (grey).

\section{PERSPECTIVES}

With a view towards potential applications, a number of proofof-concept experiments have been performed to show the addressability of SMMs on surfaces utilising scanning tunnelling microscope (STM) tips, EPR, and X-ray magnetic circular dichroism. 3,42,145,162,163 Detailed studies have been performed on SMMs placed within gold break-junctions on surfaces, for a host of $3 \mathrm{~d}, 4 \mathrm{f}$ and polymetallic molecules. ${ }^{3,42}$ The break junction allows the use of electric conductivity across the junction as a probe for the magnetic behaviour at the molecule. ${ }^{164,165}$ Many studies have focussed on $3 \mathrm{~d}$ cluster molecules at low temperature, due to their generally enhanced stability to ensure robust integrity in application to the surface. ${ }^{70}$ Other forms of isolated studies on molecules have included encapsulation in carbon nanotubes. ${ }^{166-168}$ of note, however, are the experiments performed by Wernsdorfer and coworkers, studying $\left[\mathrm{Tb}(\mathrm{Pc})_{2}\right]$ variants on surfaces and in gold junctions, examining the addressability of both electron and nuclear spin states. ${ }^{169}$ One study distinguishes between the four nuclear spin states of the central $\mathrm{Tb}^{111}$ ion, giving unique signals for each of the hyperfine transitions; ${ }^{21,169}$ this possibility lead to the first demonstration of a QIP algorithm in an SMM. ${ }^{170}$
One related study generated unique read out states of a 2-bit Ho based system. ${ }^{171}$ In this work, two Ho atoms were placed on an Au surface with a nearby Fe atom used as the probe. Upon magnetisation of the Ho atoms using the magnetic STM tip, the EPR response of the Fe atom shifts due to the neighbouring magnetic field. Assigning the two Ho atoms to the two possible states of each affords four distinct signals (local magnetic fields) at the Fe site. The shifts in the EPR spectrum are clear and unambiguous, providing a direct read out of the 2-bit memory system.

While there are as-yet no reports of surface-bound dysprosocenium cations, the isolation of the neutral $\mathrm{Tb}^{\|}$ complex $\left[\mathrm{Tb}_{(}\left(\mathrm{C}_{5}{ }^{\mathrm{P}} \mathrm{Pr}_{5}\right)_{2}\right]$, which shows record blocking and $U_{\text {eff }}$ behaviour for a non-Dy'll SMM, provides new avenues for surface studies, due to the increased volatility of neutral complexes. ${ }^{35}$

\section{SUMMARY}

The field of SMMs has grown significantly since 1993, having advanced from large polymetallic $3 \mathrm{~d}$ molecules with comparatively small magnetic anisotropy to smaller mono- or bimetallic SMMs with massive anisotropy and vastly improved magnetic memory effects. The most successful SMMs control metal coordination environments to maximise magnetic anisotropy, while simultaneously mitigating competing spinphonon relaxation processes. The next challenges lie in elucidating design criteria to minimise QTM and Raman relaxation, and developing strategies to integrate the highestperforming SMMs into prototype devices.

\section{ACKNOWLEDGEMENTS}

We thank The University of Manchester, the European Research Council (CoG-816268 for M.J.G., G.K.G. and D.P.M. and StG-851504 for M.J.G. and N.F.C.) and the Royal Society (URF for N.F.C.) for their support.

\section{RELATED ARTICLES}

eibc0117

eibc0118

eibc0166

eibc0336

eibc2009

eibc2036

eibc2156

eibc2159

eibc2220

\section{REFERENCES}

1 D. Gatteschi, R. Sessoli and J. Villain, Molecular Nanomagnets, Oxford University Press, Oxford, 2006. R. Sessoli, H. L. Tsai, A. R. Schake, S. Wang, J. B. Vincent, K. Folting, D. Gatteschi, G. Christou and D. N. Hendrickson, J. Am. Chem. Soc., 1993, 115, 18041816. 
W.-P. Chen, J. Singleton, L. Qin, A. Camón, L. Engelhardt, F. Luis, R. E. P. Winpenny and Y.-Z. Zheng, Nat. Commun., 2018, 9, 2107-2112.

F. Neese and D. A. Pantazis, Faraday Discuss., 2011 148, 229-238.

J. C. Goodwin, R. Sessoli, D. Gatteschi, W.

Wernsdorfer, A. K. Powell and S. L. Heath, J. Chem. Soc. Dalton Trans., 2000, 1835-1840.

A. M. Ako, I. J. Hewitt, V. Mereacre, R. Clérac, W. Wernsdorfer, C. E. Anson and A. K. Powell, Angew. Chem. Int. Ed., 2006, 45, 4926-4929.

S. Kang, H. Zheng, T. Liu, K. Hamachi, S. Kanegawa, K. Sugimoto, Y. Shiota, S. Hayami, M. Mito, T. Nakamura, M. Nakano, M. L. Baker, H. Nojiri, K. Yoshizawa, C. Duan and O. Sato, Nat. Commun., 2015, 6, 5955-5961.

A. Baniodeh, N. Magnani, Y. Lan, G. Buth, C. E. Anson, J. Richter, M. Affronte, J. Schnack and A. K. Powell, npj Quantum Mater., 2018, 3, 10-15. N. Ishikawa, M. Sugita, T. Ishikawa, S.-Y. Koshihara and Y. Kaizu, J. Am. Chem. Soc., 2003, 125, 86948695. and Y. Kaizu, Inorg. Chem., 2003, 42, 2440-2446. L. Sorace and D. Gatteschi, in Lanthanides and Actinides in Molecular Magnetism, John Wiley \& Sons, Ltd, 2015, pp. 1-26.

\section{A. Abragam and B. Bleaney, Electron Paramagnetic} Resonance of Transition Ions, Oxford University Press, 1970.

D. E. Freedman, W. H. Harman, T. D. Harris, G. J. Long, C. J. Chang and J. R. Long, J. Am. Chem. Soc., 2010, 132, 1224-1225.

G. A. Craig and M. Murrie, Chem. Soc. Rev., 2015, 44, 2135-2147.

D. Shao and X. Wang, Chin. J. Chem., 2020, 38, 10051018.

S. T. Liddle and J. van Slageren, in Lanthanides and Actinides in Molecular Magnetism, Wiley-VCH Verlag $\mathrm{GmbH} \&$ Co. KGaA, Weinheim, Germany, 2015, pp. 315-340.

D. Aguilà, L. A. Barrios, F. Luis, A. Repollés, O.

Roubeau, S. J. Teat and G. Aromí, Inorg. Chem., 2010, 49, 6784-6786.

M. Atzori, E. Morra, L. Tesi, A. Albino, M. Chiesa, L. Sorace and R. Sessoli, J. Am. Chem. Soc., 2016, 138, 11234-11244.

S. Thiele, F. Balestro, R. Ballou, S. Klyatskaya, M. Ruben and W. Wernsdorfer, Science, 2014, 344, 1135-1138.

T. Tezgerevska, K. G. Alley and C. Boskovic, Coord. Chem. Rev., 2014, 268, 23-40.

G. Molnár, S. Rat, L. Salmon, W. Nicolazzi and A. Bousseksou, Adv. Mater., 2018, 30, 1-23.

L. F. Chibotaru, L. Ungur and A. Soncini, Angew. Chem. Int. Ed., 2008, 47, 4126-4129.

J. Tang, I. Hewitt, N. T. Madhu, G. Chastanet, W. Wernsdorfer, C. E. Anson, C. Benelli, R. Sessoli and A. K. Powell, Angew. Chem. Int. Ed., 2006, 45, 1729-
1733.

J.-L. J. Liu, Y.-C. Chen, J.-L. J. Liu, V. Vieru, L. Ungur, J.H. Jia, L. F. Chibotaru, Y. Lan, W. Wernsdorfer, S. Gao, X.-M. Chen and M.-L. Tong, J. Am. Chem. Soc., 2016, 138, 5441-5450.

F. Guo, B. M. Day, Y. Chen, M. Tong, A. Mansikkamäki and R. A. Layfield, Science, 2018, 362, 1400-1403. H. L. C. Feltham and S. Brooker, Coord. Chem. Rev., 2014, 276, 1-33.

J.-L. Liu, Y.-C. Chen and M.-L. Tong, Chem. Soc. Rev., 2018, 47, 2431-2453.

C. A. P. Goodwin, Dalton Trans., 2020, 49, 1432014337.

K. Randall McClain, C. A. Gould, K. Chakarawet, S. J. Teat, T. J. Groshens, J. R. Long and B. G. Harvey, Chem. Sci., 2018, 9, 8492-8503.

C. A. P. Goodwin, F. Ortu, D. Reta, N. F. Chilton and D. P. Mills, Nature, 2017, 548, 439-442.

F. Donati, S. Rusponi, S. Stepanow, C. Wackerlin, A. Singha, L. Persichetti, R. Baltic, K. Diller, F. Patthey, E. Fernandes, J. Dreiser, Ž. Šljivančanin, K. Kummer, C. Nistor, P. Gambardella and H. Brune, Science, 2016, 352, 318-321.

D. S. Krylov, F. Liu, S. M. Avdoshenko, L. Spree, B. Weise, A. Waske, A. U. B. Wolter, B. Büchner and A. A. Popov, Chem. Commun., 2017, 53, 7901-7904. C. A. Gould, K. R. McClain, J. M. Yu, T. J. Groshens, F. Furche, B. G. Harvey and J. R. Long, J. Am. Chem. Soc., 2019, 141, 12967-12973. C. V. Topping and S. J. Blundell, J. Phys. Condens. Matter, 2019, 31, 013001-013027.

S. T. Liddle and J. Van Slageren, Chem. Soc. Rev., 2015, 44, 6655-6669.

R. Orbach, Proc. R. Soc. Lond. A, 1961, 264, 458-484. J. R. Friedman, M. P. Sarachik, J. Tejada and R. Ziolo, Phys. Rev. Lett., 1996, 76, 3830-3833.

L. Thomas, F. Lionti, R. Ballou, D. Gatteschi, R. Sessoli and B. Barbara, Nature, 1996, 383, 145-147.

\section{A. Fort, A. Rettori, J. Villain, D. Gatteschi and R.} Sessoli, Phys. Rev. Lett., 1998, 80, 612-615. C. J. Milios and R. E. P. Winpenny, in Molecular Nanomagnets and Related Phenomena, ed. S. Gao, Springer Berlin Heidelberg, Berlin, Heidelberg, Heidelberg, 2014, pp. 1-109. Y. Kishi, F. Pointillart, B. Lefeuvre, F. Riobé, B. Le Guennic, S. Golhen, O. Cador, O. Maury, H. Fujiwara and L. Ouahab, Chem. Commun., 2017, 53, 35753578.

G. Huang, X. Yi, J. Jung, O. Guillou, O. Cador, F. Pointillart, B. Le Guennic and K. Bernot, Eur. J. Inorg. Chem., 2018, 2018, 326-332.

F. Pointillart, K. Bernot, S. Golhen, B. Le Guennic, T. Guizouarn, L. Ouahab and O. Cador, Angew. Chem. Int. Ed., 2015, 54, 1504-1507. F. Ortu, D. Reta, Y.-S. Ding, C. A. P. Goodwin, M. P. Gregson, E. J. L. McInnes, R. E. P. Winpenny, Y.-Z. Zheng, S. T. Liddle, D. P. Mills and N. F. Chilton, Dalt. Trans., 2019, 48, 8541-8545. M. J. Giansiracusa, S. Al-Badran, A. K. Kostopoulos, G. F. S. S. Whitehead, D. Collison, F. Tuna, R. E. P. Winpenny and N. F. Chilton, Dalton Trans., 2019, 48, 10795-10798. 
J. M. Zadrozny, J. Niklas, O. G. Poluektov and D. E. Freedman, ACS Cent. Sci., 2015, 1, 488-492.

S. G. McAdams, A. M. Ariciu, A. K. Kostopoulos, J. P. S. Walsh and F. Tuna, Coord. Chem. Rev., 2017, 346, 216-239.

T. Pugh, N. F. Chilton and R. A. Layfield, Angew. Chem. Int. Ed., 2016, 55, 11082-11085.

M. A. Palacios, J. Nehrkorn, E. A. Suturina, E. Ruiz, S. Gómez-Coca, K. Holldack, A. Schnegg, J. Krzystek, J. M. Moreno and E. Colacio, Chem. - A Eur. J., 2017, 23, 11649-11661.

T. Ishizaki, T. Fukuda, M. Akaki, A. Fuyuhiro, M. Hagiwara and N. Ishikawa, Inorg. Chem., 2019, 58, 5211-5220.

J. J. Baldoví, J. M. Clemente-Juan, E. Coronado, Y. Duan, A. Gaita-Ariño and C. Giménez-Saiz, Inorg. Chem., 2014, 53, 9976-80.

K. Suzuki, R. Sato and N. Mizuno, Chem. Sci., 2013, 4, 596-600.

J. J. Baldoví, S. Cardona-Serra, J. M. Clemente-Juan, E. Coronado, A. Gaita-Ariño and A. Palii, Inorg. Chem. 2012, 51, 12565-12574.

M. A. AlDamen, J. M. Clemente-Juan, E. Coronado, C. Martí-Gastaldo and A. Gaita-Ariño, J. Am. Chem. Soc., 2008, 130, 8874-8875.

M. Shiddiq, D. Komijani, Y. Duan, A. Gaita-Ariño, E. Coronado and S. Hill, Nature, 2016, 531, 348-351.

A. Chiesa, F. Cugini, R. Hussain, E. MacAluso, G. Allodi, E. Garlatti, M. Giansiracusa, C. A. P. Goodwin, F. Ortu, D. Reta, J. M. Skelton, T. Guidi, P. Santini, M. Solzi, R. De Renzi, D. P. Mills, N. F. Chilton and S. Carretta, Phys. Rev. B, 2020, 101, 1-9.

9 E. Rousset, M. Piccardo, M. E. Boulon, R. W. Gable, A Soncini, L. Sorace and C. Boskovic, Chem. - A Eur. J., 2018, 24, 14768-14785.

R. Bircher, G. Chaboussant, A. Sieber, H. U. Güdel and H. Mutka, Phys. Rev. B, 2004, 70, 212413-212416. M. A. Dunstan, R. A. Mole and C. Boskovic, Eur. J. Inorg. Chem., 2019, 2019, 1090-1105.

A. Caneschi, D. Gatteschi, R. Sessoli, A. L. Barra, L. C. Brunel and M. Guillot, J. Am. Chem. Soc., 1991, 113, 5873-5874.

3 L. Ungur and L. F. Chibotaru, in Lanthanides and Actinides in Molecular Magnetism, Wiley-VCH Verlag GmbH \& Co. KGaA, Weinheim, Germany, 2015, pp. 153-184.

D. Maniaki, E. Pilichos and S. P. Perlepes, Front. Chem., 2018, 6, 461-488.

C. J. Milios, A. Vinslava, W. Wernsdorfer, S. Moggach, S. Parsons, S. P. Perlepes, G. Christou and E. K. Brechin, J. Am. Chem. Soc., 2007, 129, 2754-2755. D. Gatteschi, R. Sessoli and A. Cornia, Chem. Commun., 2000, 9, 725-732.

X.-Y. Wang, C. Avendaño and K. R. Dunbar, Chem. Soc. Rev., 2011, 40, 3213-3238.

S. Accorsi, A.-L. Barra, A. Caneschi, G. Chastanet, A. Cornia, A. C. Fabretti, D. Gatteschi, C. Mortalò, E. Olivieri, F. Parenti, P. Rosa, R. Sessoli, L. Sorace, W. Wernsdorfer and L. Zobbi, J. Am. Chem. Soc., 2006, 128, 4742-4755.
M. Mannini, F. Pineider, P. Sainctavit, C. Danieli, E. Otero, C. Sciancalepore, A. M. Talarico, M.-A. Arrio, A. Cornia, D. Gatteschi and R. Sessoli, Nat. Mater., 2009, 8, 194-197.

J. A. J. Burgess, L. Malavolti, V. Lanzilotto, M. Mannini, S. Yan, S. Ninova, F. Totti, S. Rolf-Pissarczyk, A. Cornia, R. Sessoli and S. Loth, Nat. Commun., 2015, 6, 82168222.

A. S. Zyazin, J. W. G. Van Den Berg, E. A. Osorio, H. S. J. Van Der Zant, N. P. Konstantinidis, M. Leijnse, M. R. Wegewijs, F. May, W. Hofstetter, C. Danieli and A. Cornia, Nano Lett., 2010, 10, 3307-3311.

M. Mannini, F. Pineider, C. Danieli, F. Totti, L. Sorace, P. Sainctavit, M.-A. Arrio, E. Otero, L. Joly, J. C. Cezar, A. Cornia and R. Sessoli, Nature, 2010, 468, 417-421. E. Burzurí, Y. Yamamoto, M. Warnock, X. Zhong, K. Park, A. Cornia and H. S. J. Van Der Zant, Nano Lett., 2014, 14, 3191-3196.

M. Murugesu, M. Habrych, W. Wernsdorfer, K. A. Abboud and G. Christou, J. Am. Chem. Soc., 2004, 126, 4766-4767.

6 S. M. Aldoshin, D. V. Korchagin, A. V. Palii and B. S. Tsukerblat, Pure Appl. Chem., 2017, 89, 1119-1143. J. M. Zadrozny, D. J. Xiao, M. Atanasov, G. J. Long, F. Grandjean, F. Neese and J. R. Long, Nat. Chem., 2013, 5, 577-581.

C. A. P. Goodwin, Dalton Trans., 2020, 49, 1432014337.

J. D. Rinehart and J. R. Long, Chem. Sci., 2011, 2, 2078-2085.

C. Görller-Walrand and K. Binnemans, Chapter 155 Rationalization of crystal-field parametrization in Handbook on the Physics and Chemistry of Rare Earths, eds K. A. Gschneidner and L. Eyring, Elsevier B.V., North-Holland, Amsterdam, 1996, pp. 121-283. N. Ishikawa, M. Sugita, N. Tanaka, T. Ishikawa, S. Koshihara and Y. Kaizu, Inorg. Chem., 2004, 43, 54985500.

Ganivet, C. R., B. Ballesteros, G. de la Torre, J. M. Clemente-Juan, E. Coronado and T. Torres, Chem. A Eur. J., 2013, 19, 1457-1465.

3 D. Tanaka, T. Inose, H. Tanaka, S. Lee, N. Ishikawa and T. Ogawa, Chem. Commun., 2012, 48, 7796-7798. S. Demir, J. M. Zadrozny and J. R. Long, Chem. - A Eur. J., 2014, 20, 9524-9529.

5 S. Takamatsu, T. Ishikawa, S. Koshihara and N. Ishikawa, Inorg. Chem., 2007, 46, 7250-7252.

Y. Chen, F. Ma, X. Chen, B. Dong, K. Wang, S. Jiang, C. Wang, X. Chen, D. Qi, H. Sun, B. Wang, S. Gao and J. Jiang, Inorg. Chem., 2017, 56, 13889-13896.

S.-M. Chen, J. Xiong, Y.-Q. Zhang, Q. Yuan, B.-W. Wang and S. Gao, Chem. Sci., 2018, 9, 7540-7545. K. R. Meihaus and J. R. Long, J. Am. Chem. Soc., 2013, 135, 17952-17957.

9 S.-D. Jiang, B.-W. Wang, H.-L. Sun, Z.-M. Wang and S. Gao, J. Am. Chem. Soc., 2011, 133, 4730-4733.

L. Ungur, J. J. Le Roy, I. Korobkov, M. Murugesu and L. F. Chibotaru, Angew. Chem. Int. Ed. Engl., 2014, 53, 4413-4417.

1 Y.-S. Meng, C.-H. Wang, Y.-Q. Zhang, X.-B. Leng, B.-W. Wang, Y.-F. Chen and S. Gao, Inorg. Chem. Front., 2016, 3, 828-835. 
J. J. Le Roy, I. Korobkov and M. Murugesu, Chem. Commun., 2014, 50, 1602-1604.

\section{J. J. Le Roy, L. Ungur, I. Korobkov, L. F. Chibotaru and} M. Murugesu, J. Am. Chem. Soc., 2014, 136, 80038010.

P. Zhang, L. Zhang, C. Wang, S. Xue, S. Y. Lin and J.

Tang, J. Am. Chem. Soc., 2014, 136, 4484-4487.

J. Sievers, Z. Phys. B, 1982, 45, 289-296.

J. G. C. Kragskow, Sievers Plot,

https://kragskow.com/sievers/.

A. Watanabe, A. Yamashita, M. Nakano, T. Yamamura and T. Kajiwara, Chem. - A Eur. J., 2011, 17, 74287432.

L. Ungur and L. F. Chibotaru, Phys. Chem. Chem Phys., 2011, 13, 20086-20090.

Y.-S. Ding, N. F. Chilton, R. E. P. Winpenny and Y.-Z. Zheng, Angew. Chem. Int. Ed., 2016, 55, 1607116074.

S. K. Gupta, T. Rajeshkumar, G. Rajaraman and R. Murugavel, Chem. Sci., 2016, 7, 5181-5191.

Q.-W. Li, R.-C. Wan, Y.-C. Chen, J.-L. Liu, L.-F. Wang, J.H. Jia, N. F. Chilton and M.-L. Tong, Chem. Commun., 2016, 52, 13365-13368.

J. Liu, Y. Chen, Y. Zheng, W. Lin, L. Ungur, W. Wernsdorfer, L. Chibotaru and M. Tong, Chem. Sci., 2013, 4, 3310-3316.

M. Gregson, N. F. Chilton, A.-M. Ariciu, F. Tuna, I. F. Crowe, W. Lewis, A. J. Blake, D. Collison, E. J. L. McInnes, R. E. P. Winpenny and S. T. Liddle, Chem. Sci., 2016, 7, 155-165.

Y. C. Chen, J. L. Liu, L. Ungur, J. Liu, Q. W. Li, L. F. Wang, Z. P. Ni, L. F. Chibotaru, X. M. Chen and M. L. Tong, J. Am. Chem. Soc., 2016, 138, 2829-2837. J. D. Rinehart, M. Fang, W. J. Evans and J. R. Long, J. Am. Chem. Soc., 2011, 133, 14236-14239.

K.-X. Yu, J. G. Kragskow, Y.-S. Ding, Y.-Q. Zhai, D. Reta, N. F. Chilton and Y.-Z. Zheng, Chem, 2020, 6, 17771793.

N. F. Chilton, C. A. P. Goodwin, D. P. Mills and R. E. P. Winpenny, Chem. Commun., 2015, 51, 101-103. H. M. Nicholas, M. Vonci, C. A. P. Goodwin, S. W. Loo, S. R. Murphy, D. Cassim, R. E. P. Winpenny, E. J. L. Mclnnes, N. F. Chilton and D. P. Mills, Chem. Sci., 2019, 10, 10493-10502.

C. A. P. Goodwin, N. F. Chilton, G. F. Vettese, E. Moreno Pineda, I. F. Crowe, J. W. Ziller, R. E. P. Winpenny, W. J. Evans and D. P. Mills, Inorg. Chem., 2016, 55, 10057-10067.

W. J. Evans, Adv. Organomet. Chem., 1985, vol. 24, pp. 131-177.

S. Demir, M. D. Boshart, J. F. Corbey, D. H. Woen, M I. Gonzalez, J. W. Ziller, K. R. Meihaus, J. R. Long and W. J. Evans, Inorg. Chem., 2017, 56, 15049-15056.

Y.-S. Meng, Y.-Q. Zhang, Z.-M. Wang, B.-W. Wang and S. Gao, Chem. - A Eur. J., 2016, 22, 12724-12731. B. M. Day, F.-S. Guo and R. A. Layfield, Acc. Chem. Res., 2018, 51, 1880-1889.

F.-S. S. Guo and R. A. Layfield, Chem. Commun., 2017, 53, 3130-3133.

S. Demir, J. M. Zadrozny, M. Nippe and J. R. Long, J. Am. Chem. Soc., 2012, 134, 18546-18549. F. S. Guo, B. M. Day, Y. C. Chen, M. L. Tong, A.
Mansikkamäki and R. A. Layfield, Angew. Chem. Int. Ed., 2017, 56, 11445-11449.

117 F. Guo, B. M. Day, Y. Chen, M. Tong, A. Mansikkamäki and R. A. Layfield, Angew. Chem. Int. Ed., 2020, 59, 18844-18844.

118 A. Lunghi, F. Totti, R. Sessoli and S. Sanvito, Nat. Commun., 2017, 8, 14620-14627.

119 A. Ullah, J. Cerdá, J. J. Baldoví, S. A. Varganov, J. Aragó and A. Gaita-Ariño, J. Phys. Chem. Lett., 2019, 10, 7678-7683.

120 P. Evans, D. Reta, G. F. S. Whitehead, N. F. Chilton and D. P. Mills, J. Am. Chem. Soc., 2019, 141, 1993519940.

121 J. M. Zadrozny and J. R. Long, J. Am. Chem. Soc., 2011, 133, 20732-20734.

122 V. V. Novikov, A. A. Pavlov, Y. V. Nelyubina, M.-E. Boulon, O. A. Varzatskii, Y. Z. Voloshin and R. E. P. Winpenny, J. Am. Chem. Soc., 2015, 137, 9792-9795. Y. Rechkemmer, F. D. Breitgoff, M. Van Der Meer, M. Atanasov, M. Hakl, M. Orlita, P. Neugebauer, F. Neese, B. Sarkar and J. Van Slageren, Nat. Commun., 2016, 7, 1-8.

124 S. Gomez-Coca, E. Cremades, N. Aliaga-Alcalde and E. Ruiz, J. Am. Chem. Soc., 2013, 135, 7010-7018. J. S. Griffith, The Theory of Transition Metal Ions, Cambridge University Press, London, New York, 1961.

126 A. V. Palii, J. M. Clemente-Juan, E. Coronado, S. I. Klokishner, S. M. Ostrovsky and O. S. Reu, Inorg. Chem., 2010, 49, 8073-8077.

127 X.-N. Yao, J.-Z. Du, Y.-Q. Zhang, X.-B. Leng, M.-W. Yang, S.-D. Jiang, Z.-X. Wang, Z.-W. Ouyang, L. Deng, B.-W. Wang and S. Gao, J. Am. Chem. Soc., 2017, 139, 373-380.

128 P. C. Bunting, M. Atanasov, E. Damgaard-M $\varnothing l l e r, ~ M$. Perfetti, I. Crassee, M. Orlita, J. Overgaard, J. van Slageren, F. Neese and J. R. Long, Science, 2018, 362, 1378-1386.

129 S. Gómez-Coca, A. Urtizberea, E. Cremades, P. J. Alonso, A. Camón, E. Ruiz and F. Luis, Nat. Commun., 2014, 5, 4300-4307.

130 J. M. Zadrozny, J. Liu, N. A. Piro, C. J. Chang, S. Hill and J. R. Long, Chem. Commun., 2012, 48, 3927-3929.

131 S. Demir, I. Jeon, J. R. Long and T. D. Harris, Coord. Chem. Rev., 2015, 289-290, 149-176.

132 M. Gonidec, E. S. Davies, J. McMaster, D. B. Amabilino and J. Veciana, J. Am. Chem. Soc., 2010, 132, 17561757.

133 I. S. Morgan, A. Mansikkamäki, M. Rouzières, R. Clérac and H. M. Tuononen, Dalton Trans., 2017, 46, 12790-12793.

134 C. Chen, Z. Hu, J. Li, H. Ruan, Y. Zhao, G. Tan, Y. Song and X. Wang, Inorg. Chem., 2020, 59, 2111-2115.

135 C. Chen, Z.-B. Hu, H. Ruan, Y. Zhao, Y.-Q. Zhang, G. Tan, Y. Song and X. Wang, Organometallics, 2020, 39, 4143-4148

136 S. Karasawa and N. Koga, Inorg. Chem, 2011, 50, 5186-5195.

137 I. A. Gass, S. Tewary, A. Nafady, N. F. Chilton, C. J. Gartshore, M. Asadi, D. W. Lupton, B. Moubaraki, A. M. Bond, J. F. Boas, S.-X. Guo, G. Rajaraman and K. S. Murray, Inorg. Chem., 2013, 52, 7557-7572. 
J. Mrozinski, J. Am. Chem. Soc., 2004, 126, 420-421.

S. K. Langley, N. F. Chilton, B. Moubaraki and K. S

Murray, Inorg. Chem. Front., 2015, 2, 867-875.

140

E. Moreno Pineda, N. F. Chilton, F. Tuna, R. E. P.

Winpenny and E. J. L. Mclnnes, Inorg. Chem., 2015,

54, 5930-5941.

141 S. K. Langley, D. P. Wielechowski, N. F. Chilton, B. Moubaraki and K. S. Murray, Inorg. Chem., 2015, 54, 10497-10503.

J.-L. Liu, J.-Y. Wu, G.-Z. Huang, Y.-C. Chen, J.-H. Jia, L. Ungur, L. F. Chibotaru, X.-M. Chen and M.-L. Tong, Sci. Rep., 2015, 5, 16621-16629.

D. N. Woodruff, R. E. P. Winpenny and R. A. Layfield, Chem. Rev., 2013, 113, 5110-48.

144 T. Morita, M. Damjanović, K. Katoh, Y. Kitagawa, N. Yasuda, Y. Lan, W. Wernsdorfer, B. K. Breedlove, M. Enders and M. Yamashita, J. Am. Chem. Soc., 2018, 140, 2995-3007.

T. Komeda, K. Katoh and M. Yamashita, in Molecular Technology, Wiley-VCH Verlag GmbH \& Co. KGaA Weinheim, Germany, 2019, vol. 3, pp. 263-304. K. Katoh, H. Isshiki, T. Komeda and M. Yamashita, Coord. Chem. Rev., 2011, 255, 2124-2148.

147 R. J. Blagg, L. Ungur, F. Tuna, J. Speak, P. Comar, D. Collison, W. Wernsdorfer, E. J. L. McInnes, L. F. Chibotaru and R. E. P. Winpenny, Nat. Chem., 2013, 5, 673-678.

D. S. Krylov, F. Liu, S. M. Avdoshenko, L. Spree, B. Weise, A. Waske, A. U. B. Wolter, B. Büchner and A. A. Popov, Chem. Commun., 2017, 53, 7901-7904. J. D. Rinehart, M. Fang, W. J. Evans and J. R. Long, Nat. Chem., 2011, 3, 538-542.

150 V. Vieru, N. Iwahara, L. Ungur and L. F. Chibotaru, Sci. Rep., 2016, 6, 24046-24053.

151 S. Demir, M. I. Gonzalez, L. E. Darago, W. J. Evans and J. R. Long, Nat. Commun., 2017, 8, 2144-2152. B. S. Dolinar, S. Gómez-Coca, D. I. Alexandropoulos and K. R. Dunbar, Chem. Commun., 2017, 53, 22832286.

P. Zhang, M. Perfetti, M. Kern, P. P. Hallmen, L. Ungur, S. Lenz, M. R. Ringenberg, W. Frey, H. Stoll, G. Rauhut and J. van Slageren, Chem. Sci., 2018, 9, 1221-1230.

154 C. Boskovic and M. Hay, Chem. - A Eur. J., 2020, chem.202003761.

155 J. A. DeGayner, I.-R. Jeon and T. D. Harris, Chem. Sci., 2015, 6, 6639-6648.

156 A. E. Thorarinsdottir, R. Bjornsson and T. D. Harris, Inorg. Chem., 2020, 59, 4634-4649.

157 X. Ma, E. A. Suturina, S. De, P. Négrier, M. Rouzières, R. Clérac and P. Dechambenoit, Angew. Chem. Int. Ed., 2018, 57, 7841-7845.

158 Y. Wang, J. Li, L. Zhang, C. Chen, R. Feng, Y. Zhao, Y.Q. Zhang, G. Tan, Y. Song and X. Wang, Dalton Trans., 2018, 47, 17211-17215.

159 U. Albold, H. Bamberger, P. P. Hallmen, J. van Slageren and B. Sarkar, Angew. Chem. Int. Ed., 2019, 58, 9802-9806.

160 F. Liu, L. Spree, D. S. Krylov, G. Velkos, S. M. Avdoshenko and A. A. Popov, Acc. Chem. Res., 2019, 52, 2981-2993.

Samoylova, M. Rosenkranz, A. Kostanyan, T. Greber, A. U. B. Wolter, B. Büchner and A. A. Popov, Nat. Commun., 2017, 8, 16098-16106. 